NASA Technical Memorandum 100637

\title{
EVALUATION OF A MULTI-POINT METHOD FOR DETERMINING ACOUSTIC IMPEDANCE
}

Michael G. Jones

and

Tony L. Parrott

June 1988
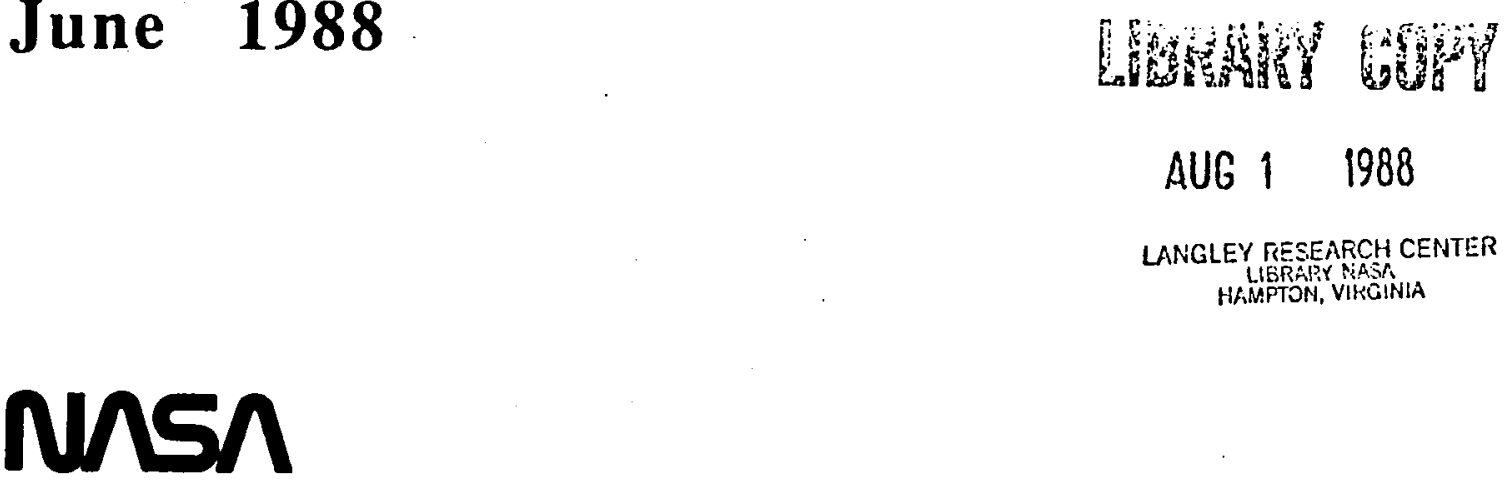

National Aeronautics and

Space Administration

Longloy Rososich Conter

Hampton, Virginia 23665-5225 


\section{ABS'TR.AC'T'}

$\Lambda_{n}$ investigation was conducted to develop and explore potential improvements provirded ly a Multi-l'oint Method (MPM) over the traditional Standing Wave Method (SWM) and 'Two-Microphone Method ('TMM) for determining acoustic impedance. $\Lambda$ wave propagation model, which inclurles wall ahsorption and mean flow, was developed lo model the slanding wave pallern in an impedance tube. The reflection fartor and acoustic impedance of a lest specimen were calculated from a 'best' fit of this slanding wave pattern to the point pressure measurements. Data was acquired with 30 test samples chosen to cover the reflection factor magnitude range from 0.004 to 0.999 . A probe inicrophone was used to obtain 2 to 6 pressure measurements per half-wavelength of the standing wave, along the crnlerline of the impedance tube. Three spacing distribution were examined; uniform, random and solective.

Slanding wave patterns calculated using the propagation modrl for all three spacing distributions match the point pressure measurements with good to excellent agreement over the cullire reflection factor magnitude range investigated. The uniform spacing distribution was preferred, however, since it was the easiest to implement and provided extremely comsistent, and repeatable results. Comparisons of the acoustic impedance determined using $2,3,6$, and 18 measurement points showed that, while two points are generally sufficient, for repeatable measurements, the most consistent results are obtained when using at least. six pressure measurements at points evenly spaced over a distance of one half-wavelength.

The effects of turbulent, mean flow noise contamination on the MPM were simulated by adding a broadband noise source to the discrete frequency source. Data were acquired at uniformly distributed points and impedances were calculated using the MPM and TMM algorithms. 'The results from these two algorithms were then compared with a reference set of MI'M results obtained with only the discrete frequency source activated. The MPM results were found to converge to the reference results with fewer averages than the TMM resillts. This observation indicates that the MPM will be superior to the TMM in the presence of signilicant, broadband noise levels associated with mean llow. 


\section{INTRODUC'TION}

The Standing Wave Method for determining normal incidence acoustic impedance has long been acclaimed as llae standard procedure for laboratory applicalions. The method relies on the fact. that, there is a unigue relationship botween the slanding wave paramelers and the test specimen impedance. The standing wave parameter measurements - standing wave ratio (SWR.) and null locations - are simple to measure, but are tedious if done manually. The availability of mini-computers made possible a degree of automation of the SWM by implementing a computer controlled, systematic search for the standing wave parameters. This search procedure, however, required many probe movements and was still lime consuming, especially if impedances at, many frequencies were desired.

Over the last 15 to 20 years much effort has been directed toward the development of more efficient methods for determining acoustic impedance. Generally, these methods rely on amplitude and phase information obtained at two or more locations in the standing wave field. Kathuriya and Munjal $|2,3|$ were arnong the first to adopt a faster, but somewhat less accurate, impedance measurement procedure in which three, fixed location pressure measurements are used to approximate the standing wave pattern with a 'graphical least squares' approach. Soon thereafter, several investigations were conducted with only two fixed location measurements, involving both pressure amplitude and phase at each frequency of interest. 'This method, called the 'Two-Microphone Method (TMM), is essentially a two parameter fit of the wave propagation morlel to the standing wave patlern. This methorl is based on a transfer function measurement between two points in the acoustic field and thus incorporates both amplitude and phase information. In actual practice, the most efficient usage of the TMM makes use of a broadband noise source $[4-6 \mid$ to simultancously determine impedances over an enlire frequency range.

The transfer function measurements can be obtained at each frequency of interest using in discrete frequency source under computer control or with a broadband source using fast fourier transform analyzers. 'The convenience of the broadband source arises from the ability of fast fourier transform analyzers to process broadband signals very rapidly. llowever, the control of the spectrum level versus frecuency is generally limited. Thus, for a given power handling capability, the maximum narrow band levels are often too low in some regions of the spectrum. A discrete frequency source, however, allows precise control of the amplitude al each frequency of interest [7], permitting a greater dynamic range to be achieved uniformly across the frequency range of interest. Thus, there are times when dise rete freguency excitation is desirable; such as deterting the onset of test specimen nonlinearily with amplitude, where a large dynamic range is needed, and in the presence of mean fow when contaminating effects of broadband flow noise may be intolerable. On the other hand, the TMM with a discrete frequency source requires computations to be 
conducted separately at each frequency of interest and, hence, increases the testing time.

The 'TMM is subject, to two major systematic errors. One systematic error occurs when the microphone separation is near one half-wavelength. 'The other is associated with amplitude and phase measurement errors. For example, to achieve impedance measurement accuracies within $3 \%$, microphone calibration errors must not exceed $0.1 \mathrm{~dB}$ and $1.0^{n}$ in amplitude and phase, respectively. The need for such precision calibration can be eliminated using a technique introduced by Chung and Pope $|8|$, in which measurements made with one orientation are repeated with the microphones (and all related circuitry) switched. Another way to avoid the need for precision calibration and microphone spacing (half-wavelength) is to use a discrete frequency acoustic excitation and sequentially posilion a single microphone at pre-sclected locations. Such sequential probe positioning can vasily be arcomplished under computer control. In fact, a control program can be implemented to sample the standing wave pattern at any number of points desired. Although the measurement time increases with the number of points sampled, both systematic and random errors should decrease.

The purpose of this investigation is to develop and explore the polential improvements in accuracy, precision and measurement efficiency provided by a Multi-Point Method $(\mathrm{MPM})$, in which from 2 to 6 pressure measurements per half-wavclength are acquired with a probe inicrophone sequentially positioned along the centerline of the impedance tube. $\Lambda$ wave propagation model describing the standing wave pattern, including effects of tube wall absorption and mean flow, allows reconstruction of the standing wave pattern. The reflection factor and, hence, the acoustic impedance of the test specimen are then determined. In conlrasl, the 'TMM is a deterministic approach in which two measurements are used to dotermine the specimen impedance. (iloarly, the two mothorls should agree when the mumber of measurement points in the MPM is reduced to two. Measurements were conducted on 30 lest samples chosen to cover the reflection factor magnitude (RFM) range from 0.004 to 0.999 in order to exercise the Ml'M in a thorough manner.

'The effect of mean flow was simulated by superimposing broadhand noise on the acoustic field generated with a discrete frequency source. It is well documented $[3,4,7]$ that the adclition of mean flow complicates impedance measurements dramatically. Not only call the mean flow change the impedance of the test specimen, it can also cause additional systematic and random errors in the measurement, process. With this in mind, the present MPM is developed with mean flow and wall absorption included in the math propagation model. Also, to insure that the actual mean flow speed experienced by the propagating sound is used in the algorithm, an iterative scheme is employed to 'adjust' the initial estimate of mean flow speed to a value that will optimize the model fit. The same procedure is employed to adjust, theoretical estimates of tube wall absorption. Fissentially, as in the 
no-flow case, the reconstructed standing wave pattern is compared to the measurement dinta in a least square sense, and the mean flow speed and tube wall absorption are varied slightly to optimize the matching of the propagation model to the measurement data. As a result of these itcrative procedures, it is expected that this method will maintain a level of acruracy in the flow regime comparable to that in the no-flow regime.

To determine the effect of measurement, point, spacing on the measured impedance values, three spacings were investigated. These consisted of uniform spacing, random spacing and selective spacing. All of the samples were tested using all three measurement point spacing procedures.

\section{ANALYSIS}

The Multi-Point Method (MPM) presented in this report combines the strengths of the Standing Wave Method (SWM) and the Two-Microphone Method (TMM) while avoiding some of their inherent weaknesses. The SWM is generally used as a standard against which to compare the accuracy of any new technique, since it involves direct measurement of standing wave ratios and null positions of the standing wave pattern. This procedure is illustrated graphically in Fig. 1. The TMM uses the complex ratio of the acoustic pressures at two locations in the standing wave pattern (i.e., the transfer function) to directly compute the impedance, so that the measurement process can be accomplished without physical movement, of the hardware. Major disadvantages of the TMM are; (1) requirement of procise physical positioning and amplitude/phase calibrations, and (2) systematic errors associated with spatial separations near one half-wavelength. The MPM avoids these disadvantages by employing a least squares fitting technique to fit a wave propagation tnodel to the point measurements. This procedure should exhibit uniform accuracy for all wavelengths of interest.

The pressure distribution for a plane wave propagating in a tube is given by

$$
P_{j}=\left|P_{i} e^{i \Gamma_{i} \tau_{j}}\right| P_{r} e^{i \Gamma_{r} x_{i}} \mid e^{-i \omega t}
$$

where $I_{j}$ is the complex pressure (amplitude and phase) measured al positions $x_{j}$, and $P_{i}$ and $l_{r}$ are the incident and reflected pressures, respectively. The incident, and reflected plane wave propagation constants, $\mathrm{l}_{i}$ and $\mathrm{l}_{r}$, are defined as

$$
r_{i} \therefore k_{i}+i \alpha_{i}
$$

and

$$
\Gamma_{r}=-\left(k_{r}+i \alpha_{r}\right)
$$


where the incident. and reflectod wave mumbers in mean flow are given hy

$$
k_{i}-\frac{\left(\omega / c_{t}\right)}{(1+M)}
$$

and

$$
k_{r}=\frac{\left(\omega / c_{t}\right)}{(1 \cdot M)}
$$

In these relations $\omega$ represents the angular frequency, $c_{t}$ is the sound speed in the tube, and $M$ is the mean flow Mach number taken to be positive in the $(\%)$ coordinate direction.

lngard and Singhal $|9|$ estimate the incident and reflected tube wall absorption coefficients $\left(\alpha_{i}, \alpha_{r}\right)$, which include the effects of mean flow, in the following manner:

$$
\begin{aligned}
& \alpha_{i}=\frac{\left(\beta_{v}+\beta_{t}\right)}{(1+M)} \\
& \alpha_{r}=\frac{\left(\beta_{v}+\beta_{t}\right)}{(1-M)}
\end{aligned}
$$

The quantities $\beta_{n}$ and $\beta_{t}$ account for viscothermal and turbulence dissipation of acoustic cnergy at the tube walls and are calculated as follows:

$$
\begin{gathered}
\beta_{1}=\frac{\sqrt{2}}{4 a_{0}}\left(\begin{array}{c}
\omega \\
\cdots \\
c_{t}
\end{array}\right)\left[\frac{\sqrt{\mu}}{\omega}+(\gamma-1) \sqrt{\frac{\kappa / c_{p}}{\rho \omega}}\right] \\
\beta_{l} \frac{\frac{\psi M}{2 a_{11}}(1 /|1| 0.869 \sqrt{\psi} \mid)}{}(1)
\end{gathered}
$$

where $\gamma$ represents the specific heat ratio at constant density and volume, $\rho$ and $\mu$ are the density and viscosity of the fluid, $\kappa$ is the heat conduction coefficient, and $c_{p}$ is the specific. heat at a constant pressure. The ratio of the duct area to the perimeter is $a_{0}$, and $\psi$ is the cocfficient of friction for turbulent, flow $|10|$, which is calculated numerically from the Prandt.l universal resistance law

$$
\frac{1}{\sqrt{\psi} ;},-2 \log _{10}(\operatorname{Re} \sqrt{\psi} \psi)-0.8
$$

where Re is the flow Reynolds number.

'lhe propagation model given by equation (1) can be fitted to a distribution of $N$ measured pressures, $P_{j}$, by minimizing the function

$$
F\left(P_{i}, P_{r}\right)=\sum_{j=1}^{N}\left(P_{j} \quad P_{i} e^{i \Gamma_{i} x_{j}} \cdot P_{r} e^{i \Gamma_{,} x_{i}}\right)^{2}
$$


where the harmonic time dependence $\left(e^{i \omega t}\right)$ has been suppressed. To minimize $F\left(P_{i}, P_{r}\right)$ the following conditions are imposed:

$$
\begin{aligned}
& \frac{\partial F^{\prime}}{\partial P_{i}}=0 \\
& \frac{\partial F}{\partial P_{r}}=0
\end{aligned}
$$

Substitution of equation (11) into equations (12) and (13) and solving for the incident and reflected pressures yields

$$
P_{i} \cdot \frac{C E-A B}{D E \cdot A^{2}}
$$

and

$$
P_{r}=\frac{C-P_{i} D}{\Lambda}
$$

where

$$
\begin{gathered}
A=\sum_{j=1}^{N} e^{i\left(\Gamma_{i}+\Gamma_{r}\right) x_{j}} \\
B=\sum_{j=-1}^{N} P_{j} e^{i \Gamma_{r} x_{j}}, \quad C=\sum_{j=1}^{N} P_{j} e^{i \Gamma_{i} x_{j}} \\
D=\sum_{j=1}^{N} e^{2 i \Gamma_{i} x_{j}}, \quad B=\sum_{j=1}^{N} e^{2 i \Gamma_{r} x_{j}}
\end{gathered}
$$

In order to simplify the physical description of the standing wave consider the reflection factor, RF', given by

$$
\text { R.F } \quad \begin{aligned}
& P_{r} \\
& P_{i}
\end{aligned}
$$

Finally, the acoustic impedance, $\zeta$, at the face of the specimen is given by the relation

$$
5 \quad \frac{1}{1}+\frac{R F}{R F}
$$

$\Lambda$ check on the accurary of $R F$ can be obtained by comparing the reconstructed standing wave pattern calculated from the $P_{j}$ measurements with the directly measured standing wave pattern. 


\title{
WXPERIMENTAL, SETUP ANI) T'WST PROCFIOURE
}

\author{
Impedance Tube Description
}

'The Multi-Point. Method (MPM) described in the AN $\Lambda$ LYSIS section was implemented in a square cross-section $(5.08 \mathrm{~cm}$ by $5.08 \mathrm{~cm}$ impedance tube. A photograph of lhe tube is shown in Fig. 2, and a schematic illustrating the apparatus in more detail is shown in Fig. 3. The tube is $58.4 \mathrm{~cm}$ in length. Two 75-watt, phase matched acoustic drivers generate signals over a frequency range of 0.3 to $3.0 \mathrm{kHz}$, with SPL's up to $140 \mathrm{dH}$ at. the lest specimen surface. The test specimen is carefully clamped to the exit plane of the impedance tube with the aid of a rubber gasket. The geometry of the apparatus is such that plane waves propagate down the tube to the face of the test specimen. These plane waves are reflected by the test specimen and create a standing wave pattern that wniquely characterizes the normal incidence acoustic impedance of the specimen. An $0.635-\mathrm{cm}$ condenser-type microphone, flush mounted in the top wall $0.635 \mathrm{~cm}$ from the fest specimen face, is used to measure the reference levels to insure that the desired test, environment is present. A traversing microphone probe can be positioned at the centerline. over approximately $28.8 \mathrm{~cm}$ of the tube length to acquire acoustic pressure data along the slanding wave.

\section{Traversing P'robe Description}

'To accurately mensure 'point,' pressures in a standing wave field by means of a probe tube, spurious sound arising from transmission through the probe tube walls must be minimized. The traversing probe (Fig. 4) was fabricated from a 83.82-cm long stainless stewl tube with outer and inner diameters of 0.16 and $0.08 \mathrm{~cm}$, respectively. The probe was coupled to an $1.27-\mathrm{cm}$ condenser-type microphone via a flexible tube, and could be positioned within $0.025 \mathrm{~mm}$ of the specified loration. The four $0.071-\mathrm{cm}$-diameter probe lube ports, equally spaced around the probe in a single measurement planc located $1.42 \mathrm{~cm}$ from the probe tip, could be positioned over a range of $1.7810 .30 .58 \mathrm{~cm}$ from the test spereimen farce.

'Io determine the effects of transmission through the probe walls, measurements were taken with the probe ports located in a de(e) null produced by a nearly perfect reflector (sterel plate). Since the ports were located in the plane of a decp mull, any sound transmission through the probe tube walls would tend to increase the apparent signal level at the mull locations and, thus, decrease the dynamic range of the measurement system. The measurement was conducted at a high amplitude (approximately $130 \mathrm{~dB}$ ) for six frequencies from 0.5 to $3.0 \mathrm{kHz}$. Measurements were conducted with the ports open and closed (multiple layers of tape used to seal measurement ports). The effects of wall transmission on the probe performance were determined from the ratio of the open-port to closed-port. 
response. The results of this measurement, are illustrated in Fig. 5, in which the ratio of the open-port probe response to the closed-port response is plotted in dB versus frequency. Since the open-port response is at least $32 \mathrm{~dB}$ above that of the rlosed-port response, it is clear that contaminating effects due to sound transmission through the tube walls are negligible over the frequency range of interest.

\section{Instrumentiation}

$\Lambda$ block diagram of the signal conditioning instrumentation and data processing syst.em for the acoustic signals is shown in Fig. 6. At each test frequency, an SPL was set. at the reference microphone via a computer-controlled frequency synthesizer. Acoustic pressures were then obtained at a number of axial locations. These axial pressures were then inserted as $P_{j}$ into the appropriate expressions in equation (16) in order to compute the incident and reflected pressure levels, as given in equations (14) and (15). The reflection factor and acoustic impedance of the test specimen were then computed at the lest frequency using equations (17) and (18). Contributions from broadband noise were minimized by band-pass filtering and signal enhancement. The amplitude and phase of the excitation frequency were obtained with an on-line fast Fourier transform routine.

\section{Measurement P'oint Distributions}

In order to determine the optimum distribution (spacing and number) of measurement points over the standing wave pattern, three distribution were examined. The distributions chosen were (1) uniform spacing, (2) random spacing, and (3) selective spacing based on location of maxima and minima of the standing wave pattern. The uniform spacing distribution is the simplest to implement. However, it may not yield the most uniform accuracy over a wide range of wavelengths and test specimen reflection factors. Since such uniform accurary is a desirable goal, the other two more complex measurement point distribulions were also investigated.

The uniform spacing distribution was employed to obtain data for all of the available test specimens. The goal was to obtain 6 uniformly spaced points per half-wavelength (maximum of 3 half-wavelengths) in order to obtain an accurate least, squares curve fit. Since the wavelengths associated with the lower frecuencies are greater than the available axial moasurcmont range, a minimum of 10 data points (uniformly distributed over the available range) was used. The usage of more than two points per half-wavelength also , avoids the ill-conditioned solution for the rellection factor; via equation (1), which occurs when only two measurement points are used that are near ono half-wavelength apart.

It a similar manner, acoustic impedances were obtained using randomly selected measurement locations. Again, the tolal number of data points ranged from 10 to 18 . Also, for this spacing distribution an additional constraint was imposed such that at least two 
measurements per $\frac{1}{i}$ wavelength were taken. In other words, ach hall-wavelength was divided into 3 equal segments, and a random number generator was used to determine two measurement localions within each segment.

The selective spacing distribution was the same as the uniform spacing distribution, with additional data acquired at each peak and null encountered in the standing wave patl,orn. Il, was expected that significant data quality improvement could be obtained by including measurements at pressure nulls, which tend to bo very sharp and deep for specimens with large rellection factor magnitudes (c.g., stecl). In the present configuration, sclective spacing has two limitations; (1) spatial resolution due to the finite area of the probe ports, and (2) finite step size in the search procedure algorithm. Due to these limilations, null locations may not have been located as precisely as intended. In fact, when the standing wave null is very sharp, data acquired in these sensitive regions may artually degrade the accuracy of the overall results.

\section{Impedance Measurement Valiclation Range}

The 30 different test specimens included mostly resonant type absorbers, whose structural features differ in detail to cover a.wide range of reflection factor magnitudes $(0.004$ $\because$ IRFM $<0.999)$. 'To obtain the smallest possible RFM, a foam wedge was used, whereas the large R.FM's were obtained with a steel specimen. 'The intermediate range of RFM's was obtained via ceramic honeycomb, a rigid structure of isolated, small diameter parallel channels which provided a very stable and linear impedance. This variety of test specimens allowed the propagation model, described in the $\Lambda$ NALYSIS section, to be exercised for at wide range of impedances. Obviously, if the impedance values obtained using the MIM are shown to be repeatable, consistent, and converge uniformly to previous results obtained by other methods, the MPM will be validated.

\section{Simulated Flow Noise Elfects}

In some applicalions, acoustic impedance measurements are necessary in the presence of mean flow. The presence of mean flow will tend to exaggerate differences in the measured impedance using the different spacing distributions. Thus, it is of interest to determine the effect of How noise on the accuracy of the MPM. Mean flow effects on impedance measurements can be identified either as intrinsic changes in the test specimen impedance due to the mean flow or as a deleterious effect on the measurement process itself, such as lhe increased background noise level generated by flow turbulence. It is critically imporlant that, the t,wo effects be separated. Many materials exhibit nonlinear behavior in the presence of mean llow, which causes changes in the acoustic impedance of a test specimen $|11-12|$. 
In this investigation, the noise contamination aspects of turbulent, flow were simulated on three specimens that exhibited linear behavior over the SPL range available in the test apparatus. The three test specimens investigated (steel, foam wedge and ceramic honcycomb) were chosen to study the effect of simulated flow noise on the measurement process over a large RFM range. A series of tests were conducted in which a broadband noise background was introduced to 'contaminate' the discrete test frequencies. This was accomplished by exciting one of the two drivers with signals from a broadband noise generator. The discrete frequency standing wave pattern was then extracted from the combined response by using an ensemble averaging technique, and the acoustic impedances were determined with the MPM.

\section{RESULTS AND DISCUSSION}

In this section the terms acoustic impedance, reflection factor, and standing wave ratio are used somewhat interchangeably. This is due to the fact that the three parameters are directly related. As will be seen in the discussion, certain topics can be more conveniently described in terms of a particular choice of one of these parameters.

\section{Curve-Pitting Comparison}

Fig. 7 depicts SPl, and phase distributions versus axial distance. These data were acquired by applying each of the three measurement point spacing distributions to three t.est. specimens. whose SWR's varied from 0.2 to 40 dl3 (0.004 R. RM ? 0.999). Fig. 7(a) shows results for an intermediate SWR range, and Figs. $7(b)$ and $7(c)$ show results for large and small SWIR's, respectively. The measured values are represented by the circles and the solid line represents the least squares wave propagation model fit to the data. The same test frequency of $2 \mathrm{kH} \%$ is shown for all three test specimens. 'The results are plotted from $x=-30.5$ to $x$. $0 \mathrm{~cm}$, with the specimen placed at $x$ : $0 \mathrm{~cm}$ and the upstream source located at about, $x: 63.5 \mathrm{~cm}$.

Fig. 7 (a) demonstrates the ability of the three measurement point distributions to reconstruct the standing wave pattern characteristic of a sample with a 10 dB SWR (RFM near (0.5). For samples of this type, the three measurement point distributions provide nearly iclentical results. These results were repeatable for virtually all of the samples with SWR's between about 1 and 25 dH. This was expected, since the discrete frequency sound source was very stable and a sizable number of averages (500) were used to determine the acoustic pressure at cach position. This mumber of averages was not necessary to attain arceptable results (and thus, a good signal-to-noise ratio), but was used because of the convenience and speed of the data acquisition system. 
Fig. $7(b)$ shows the reconstructed standing wave pattern for a steel sample characterized by large SWR's ranging from 30 t.o 40 dB (RPM near 1.0). Again, both the SPI, and phase match almost all of the data points accurately. Somewhat surprisingly, the uniform spacing distribution provides a more typical representation of the standing wave palifern (nulls gradually increase as sound propagales away from the face of the specimen) than does the selective spacing distribution. This may be due, in part, to the difficulty of aclually locating and measuring the absolute minima with the selective spacing distribulion, as discussed previously. Overall, the three curves appear quite similar and, as will be discussed later, provide nearly identical rellection factors.

lig. $7(c)$ shows results acquired with a foam wedge test specimen characterized by very low SWR's of about 0.2 dB (RFM of 0.004 ). 'This specimen was chosen to exercise the MPM all small R.F'M's. Contrary to the results from samples with larger R.FM's the math model least squares fit procedure does not fit the amplitude data as well, in contrast with the phase data, which is still described very well by the math model. This degradation of the amplitude fit is believed due to numerical problems associaled with small reflected wave amplitudes. However, the overall quality is still good (see Fig. 8(b)) in that the deviations between the measured data and the curve fit are no more than about $0.05 \mathrm{~dB}$ for any of the measurement point distributions. Also, it should be noted that curve fits to each sel of phase data are consistent from onc spacing distribution to the other.

\section{Comparison of Ml'M with TMM and SWM}

$\Lambda$ ilirect comparison of the MPM with the TMM can be obtained by computing the imperance using the 'TMM algorithm on any subset of two measurement points of the MPM dalia for a given sample. Fig. 8 depicts acoustic impedances (resistance and reactance) arepuired from uniform, random and selective spacing distributions. It also includes results oblinined via the 'l'MM algorithen from the two uniform spacing measurement points nearest the test specimen (denoted with diamonds). These measurement points were chosen to avoid the ill-conditioning which occurs in the 'TMM algorithm for sparings near one halfwavelength. 'Typical results are shown from ach of six types of test specimens to fully denomstrale the MPM capabilities. In addition. Fig. $8(f)$ includes results which had been ohtained carlior with the SWM (denoted with X's).

Ilighly refloclive materials are often chosen to simulate ground surfaces in scale model propagation studies |13|. When studying materials which have rather large SWR's it is gencrally more moaningful to compare results based on the rellection factor. This is illustrated in Fig. 8(a) for a steel specimen, in which both the reflection factor and impedance comparisons are included. As secn in this figure, highly reflective materials generally produce significant scatter on an acoustic impedance plot, while converging quite well when depicled in the rellection factor regime. On tho other hand, materials with SWR's less than 
about 25 dB tend to be less sensitive to small changes in the standing wave parameters and, hence, can be compared very well on the basis of acoustic imperlance (e.g. Fig. 8(b)).

Fig. 8(c-f) depicts results obtained with samples with moderate R.PM values of 0.1 to 0.9. lior these cases il is expected that the acoustic impedance results should be consistent. from one method to another. However, there are detectable differences between the results from each of the spacing distributions and the results from TMM code. Fig. 8(c) shows some of the best run-to-run consistency, obtained with a ceramic honeycomb sample. These resulls indicate that all three measurement point distribution scherres of the MPM and the 'TMM results are about equally reliable for 'well behaved' test specimens over a large range of impedance values. This is not surprising, since the clamping arrangement for this specimen was very repeatable and the ceramic honeycomb is a stable, linear material.

Since the results for the TMM were obtained using a two-point subset of data obtained with the uniform spacing distribution, the good comparison betwern the TMM and the MPM (uniform spacing) indicates that the MPM does not degrade the results. This observation suggests that the MPM may be a superoir method for the measurement of acoustic impedance because it avoids the ill-conditioning problems associated with the TMM method. The observed variance between the uniform spacing results and the other two sparing distributions suggests the possibility of an optimum spacing distribution. To delermine the best of the three spacing distributions in this investigation, an additional data set, was included on Fig. 8(f), which was taken using the SWM. 'This data was acquired over a reduced frequency range since the previously acquired SWM data was taken over that range. The results were found to track the results of the uniform spacing distribution and the 'TMM quite well, indicating that the uniform spacing distribution is the best of the three measurement point distributions studied in this experiment.

()verall, all threc of the spacing distributions provided the same general trends. Therefore, the choice of a spacing distribution should not be an overriding concern unless extremely accurate data is recpuired. Although SWM results were not available for all of the dala sets, a test was conducted in which the probe was inanually traversed to locate the maxima and minima in the standing wave patlern. The levels and locations of the extrema were compared to results obtained by applying the MPM analytical model to each spacing distribution. 'The agreement between the two procedures indicated that the MPM, which is quite simple and eflicient, is comparable to the SWM. Finally, to demonstrate the repeatability of the MPM, a fibermetal sample was tested using uniform spacing for three runs. As shown in Fig. 9, the data are extremely repeatable.

\section{MPM - Llow Many Points Per Half-Wavelength?}

Another goal of this investigation was to determine the relationship between the number of dala points and the quality of impedance measurements. The uniform spacing dis- 
tribution dala described in ligh. 7 was used for this study. As usual, the data set contained a minimum of six points per cycle ( $\frac{1}{2}$ wavelenglh), with up to three cycles included. 'The: results of these mousurements are represented by squares in lig. 10. 'The second set of results (depicted with circles) was computed using only the six moasurements closest to the specimen. Finally, two additional sets of results were computed by using three (first, third and fifth points) and two (first and fourth points) points from the first cycle, depicted with triangles and diamonds, respectively. It should be noted that the usage of only two measurement points reduces the algorithm to a deterministic calculation of the impedance, similar to the 'TMM.

As shown in Fig. $10(a, b)$, the number of points per cycle does not significantly affect the result.s for samples with RFM's which are not large. This is a very important observatien, since it indicates that quite repeatable results can be obtained for a vast majority of samples with as few as two properly positioned acoustic pressure measurements per cycle.

$\Lambda$ s previously discussed, samples with large RFM's are generally compared directly on the hasis of reflection fartors. When studied in this manner, Fig. 10(c) further substantiates the conclusion that two points per cycle are generally sufficient for accurate resulls. However, there is a slight improvement when additional pressure measurements are included. Thus, since cach pressure measurement requires a minimal amount of time, it is recommended that six points (one cycle tolal) be used when possible.

\section{Simulated flow Noise Results}

The final portion of this investigation was to examine one effect of flow noise on the measurement process. 'To accomplish this goal, a number of measurements were made will a broadband noise source combined with the discrete frequency source to simulate the noise contamination present with moan flow. The broadband noise source was set. to a level where differences between TMM and MPM results appeared, which occurred at. a level such that the ratio of discrete frequency level to overall broadband noise level was approximatcly 2 dB. Fig. 11 shows the hroadband noise spectrum at the reference mirroplones with a typical lest frequency level superimposed at, $1.5 \mathrm{kHz}$. lig. 11(a) shows the combined spectrum for a highly absorbing test matcrial, whereas Fig. 11(b) shows the rombined spectrum for a highly reflecting test. material. It should be noted that the longiludinal resonances of the impedance tube tend to accentuate corresponding frequencies in the broalhand excitation, thus generating a number of spectrum peaks other than that associated with the discrete frefuency source. 'This broadband noise produces the same effect as observed with low velocity monn flow, i.e. it tends to submerge the test frequency spectral line in the broadband noise. In the case of the small RFM material (fig. $11(a)$ ) the discrete frequency level was well above the broadband levels (from about, 15 to 30 , 13 , depending on choice of discrete frequency), whereas for the large RFM ma- 
terial (Fig. $11(b)$ ) frequencins corresponding to the resonances werc also present at levels of 10 to $15 \mathrm{db}$ above the broadband noise.

The uniform spacing distribution was again used to acquire data for the three samples described in Fig. 7 (materials with typical, small and large RFM's), with the usual number of points per cycle. For comparison purposes, a roference data set (represented by square symbols) was acquired without the broadband noise included. 'The broadband noise source was then activated and the pressure data were acquired with the maximum possible number of data points. 'The results of this data set are depicted by the circles in Fig. 12. Two data points were then taken from this same data set. (broadband noise source activated) and inpul, into the math propagation model (represented by triangles) to compare with results from multiple data points. 'These two points were chosen from the total data set such that, they were $\frac{1}{4}$ wavelength apart. Since the MPM math propagation model reduces to the 'TMM algorithm with the usage of only two data points, these two-point results represent TMM results under the best, possible conditions. By using a single transducer, calibration crrors have been eliminated. Also, by choosing the spacing of the measurements properly, the best possible results from the two-point data should be achieved. The overall effect, of this procedure is to demonstrate the capabilities of the MPM versus the best available with the TMM.

A mumber of conclusions can be drawn from the results of Fig. 12(a,b) for materials with typical and small RFM's. The MPM results with the broadband noise fall very close to the results obtained without broadband noise. In general, the TMM results (with broadband noise) also come reasonably close to the other data. IIowever, the TMM results do not. match with the 'elean' results (discrele frequency source only) as well as the MPM results. further tests with the same materials, which are not shown in the figures, indicate that the 'IMM results gradually approach the MPM results as the number of averages is incrosed (and hence, as the signal-to-nosise ratio is increased). 'Therefore, for this arrangement, the major improvement of the MPM over the 'TMM is the need for fewer averanges to attain equally consistent resilts.

The resulls of lig. $12(\mathrm{c})$ are for a hard surface (large R.FM). Again, these types of material are compared on the basis of reflection factors. As was noted in the results of lig. 12(a,b), the 'TMM is not quite as consistent as the MPM, but is not dramatically different.

It is expected that the inclusion of actual moan flow (as opposed to the simulated mean llow used in this study) will complicate the measurement process to such a degree that the disparity between the MPM and the TMM will be significantly increased. In the usual applicalion of 'TMM, lixed microphone locations are employed to avoid the mechanical inconvenience of probe movement. The noed for precise calibration can be eliminated by 
microphone switching. However, this will not likely produce the same data quality as a single probe traversed belween two points. ()n the other hand, if probe movement is available, there is no roason not lo use at loast .3 points within the first half-wavelength lo avoid the ill-conditioning problem. In order to avoid calibralion difliculties, TMM data. can be taken with a single microphone sequentially positioned to two desired locations. C'learly, the accuracy of 'TMM results is limited by the capability of precisely determining the mean flow velocity, whereas the MPM iterative scheme corrects for possible deficiencies in this measurencnt. Also, while the re-positioning is occurring, slow drift in the mean flow, if present, will likely cause the results of the TMM to be distorted. On the other hand, the MPM, which tends to average over oscillations of the mean flow, is designed to minimize the adverse effects of the mean flow drift, and, hence, should provide a more accurate result. It is intended that, this premise will be investigated in future tests.

\section{CONCLUDING: REMARKS}

An experiment, was conducted to compare a Multi-Point Method (MPM) for determining aconstic impedances with two reliable methods, the Standing Wave Method (SWM) and the 'l'wo Microphone Method (TMM). A significant, number of test materials were sturlied to test. the MP'M over a range of RFM's from 0.004 to 0.999. Acoustic pressures along lihe centcrline of the impedance tube were measured with three measurement point spacing distributions; uniform, random and selective. $\Lambda$ least squares fitting method, with the tube wall absorption and mean flow included, was used to model the standing wave piltiern. From this standing wave pattern the complex reflection factor of the test specimen was delermined. Some conclusions from this investigation aro presented in the following serdion.

Standing wave patterns calculated with the propagation model for all three spacing distributions were found to match the measurements with good to excellent agreement, over the entire RFM range. Mantually positioned acoustic pressure measurements were used to show that the MPM is comparable to the SWM. In addition, a two-point subset of uniform spacing dala, carcfully chosen to avoid spacings noar a half-wavelength, was input into a TMM algorithm. Acoustic impedances, computed from data for each of the spacing distributions, were then compared with results of the 'TMM and SWM. The random and selective spacing impedances were found to agree with the TMM and SWM with acceptable consistency. The uniform spacing distribution, however, was observed to provide extremely consistent results. The uniform spacing impedance data was also shown to be very repealable and, thus, a superior measurement point distribution to be used with the MI'M. 
Next, a study was conducted to determine the mumber of dala points necessary to properly define the acoustic pressure distribution. Comparisons were made between results nsing 2, 3, 6, and is dala points which showed that, in general, only two properly located moasurement points are required for repealable measurements.: However, it was shown that. the most consistent MI'M results are obtained by using at least six acoustic pressure measurements evenly spaced across one half-wavelength.

Finally, an investigation was conducted to determine the effects of contamination due to the turbulent, mean flow noise on the MPM. 'To simulate this flow noise, a broadband noise source was added to the diserete frequency source. A set of data was then acquired with the uniform sparing distribution and input into the MPM. In addition, a two-point subset of the same data was input into a TMM algorithm. The results from these two methods were then compared with a reference set of MPM results obtained with only the discrete frequency source activated. The TMM results (with the broadband noise) were obscrved to approach the reference results as the number of averages was increased. However, the MIM results were found to converge to the reference results with fewer averages. This indicates that the MPM will be a better choice in the presence of mean flow: He also indicates that the 'ТМM may be sufficient in the presence of mean flow, if a significant mumber of averages is used, and if the mean flow is very stable.

Ii conclusion, the overall purpose of this investigation, which was to develop and explore the potential improvements on accuracy, precision, and measurement efficiency afforder by the MI'M, has heen satisfied. Three acceptable measurement point spacing distributions have boen demonstrated, but the best appears to be the uniform spacing. Since the MPM is fast and efficient, especially when used in conjunction with the uniform spaciug measurement point distribution, it may well be a preforable method for future expreriments.

\section{R FEFRENT:FS}

1. W. K. R. lippert 195.3 Acustica 3, 153-160. The practical representation of standing waves in an acoustic impedance tube.

2. M. L. Kalluriya and M. L. Munjal 1977 Journal of the Acoustic Socicty of America (32, 75, 1-75.1. Measurement of the acoustical impedance of a black box at low frequencies using a shorter impedance tube.

3. M. L. Kathuriya and M. L. Munjal 1977 Journal of the Acoustic Society of America 62, 755-759. Method for evaluation of the acoustical impedance of a black box, with or without mean flow, measuring pressures at fixed positions.

4. D). A. Blaser and J. Y. Chung 1978 Inter-Noise, 901-908. A transfer function technique for determining the acoustic characteristics of duct systems with flow. 
5. A. F. Seybert and T. I. Parrott 1978 NASA TM-78785. Impedance measurement using a two-microphone; random-excitation method.

6. J. Y. Chung and J. Y. Blaser 1980 Jonrnal of the Acoustic Sociely of Annerica 68, 907921. Transfer function method of measuring in-duct acoustic properties. I. Theory and II. Experiment.

7. A. F. Scybert and I). li. Ross 1977 Journal of the Acouslic Sociely of America 61, 1362-1370. Experimental determination of acoustic properties using a twomicrophone, random-excitation technicque.

8. J. Y. Chung and J. Pope 1978 Inter-Noise, 893-899. Practical measurement of acouslical inlensity - the two-microphone cross-spectral method.

9. U. Ingard and V. K. Singhal 1974 Journal of the Acoustic Socicty of America 55, 535538. Sound attenuation in turbulent pipe flow.

10. s. W. Yuan 1967 Foundations Of Eluid Mechanics. pp. 383-384. Englewood Cliffs, New Jersey: Prentice-Hall, Inc.

11. W. E. Zorumski and B. J. Tester 1976 NASA TM X-73951. Prediction of the acoustic impedance of duct liners.

12. A. S. Hersh and B. Walker 1978 NASA CR-2951. Fiffects of grazing flow on the stoudy-state flow resistance and acoustic: impedance of thin porous-faced liners.

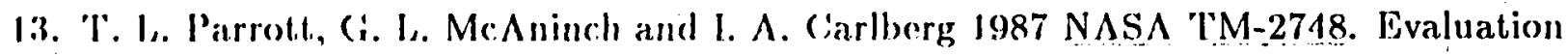
of a scale medel experiment to investigate long range acoustic propagation.

\section{APPHNI)IX: NOMLAN(:L,AIURL}

n.1 ratio of duct area to duct perimeter

r: free spare sound spoed

r. specific heat at constant pressure

c, sound spered in tube.

$\int$ frepuency

$i \sqrt{ } \quad \sqrt{ }$

$k: \quad \quad \omega / c$, wave number in frece space

$M$ monallow Machs number

$N \quad$ total number of data points

l' acoustic pressure

$P_{\text {", }} \quad$ measured acoustic pressure with open ports

P.p measured acoustic pressure with closed ports

Re. Rrynolds number 


\begin{tabular}{|c|c|}
\hline 1 & lime \\
\hline$r$ & axial position in tost section \\
\hline \multicolumn{2}{|c|}{ cirorok } \\
\hline or & alsorption coeflicient \\
\hline$B_{1}$ & turbulence absorption coeflicient \\
\hline$\beta_{n}$ & viscothermal absorption coefficient \\
\hline$r^{\prime}$ & plane wave propagation constant. \\
\hline$\gamma$ & specific heat ratio \\
\hline$s$ & acoustic impedance, normalized by or: \\
\hline$\kappa$ & heat conduction coeflicient \\
\hline$\mu$ & Iluid viscosily \\
\hline r & Nluid density \\
\hline$y$ & cocllicient of friction for turbulent flow \\
\hline$\omega$ & $2 \pi \int$, allgular frecfucncy \\
\hline \multicolumn{2}{|c|}{ Subscripts } \\
\hline$i$ & incident component \\
\hline$j$ & data point counter, $j \quad 1,2,3, \ldots, N^{\prime}$ \\
\hline$r$ & reflected romponent \\
\hline \multicolumn{2}{|c|}{ Ahbroviations } \\
\hline MI'M & Multi-l'oint Method \\
\hline $\mathrm{RF}$ & Reflection lactor \\
\hline RWM & Rellection Pactor Magnitude \\
\hline Sill, & Sound Pressure level \\
\hline$S W M$ & Standing Wave Mothod \\
\hline SSWR & Standing Wave Ratio \\
\hline 'TMM & Two Mierophone Method \\
\hline
\end{tabular}




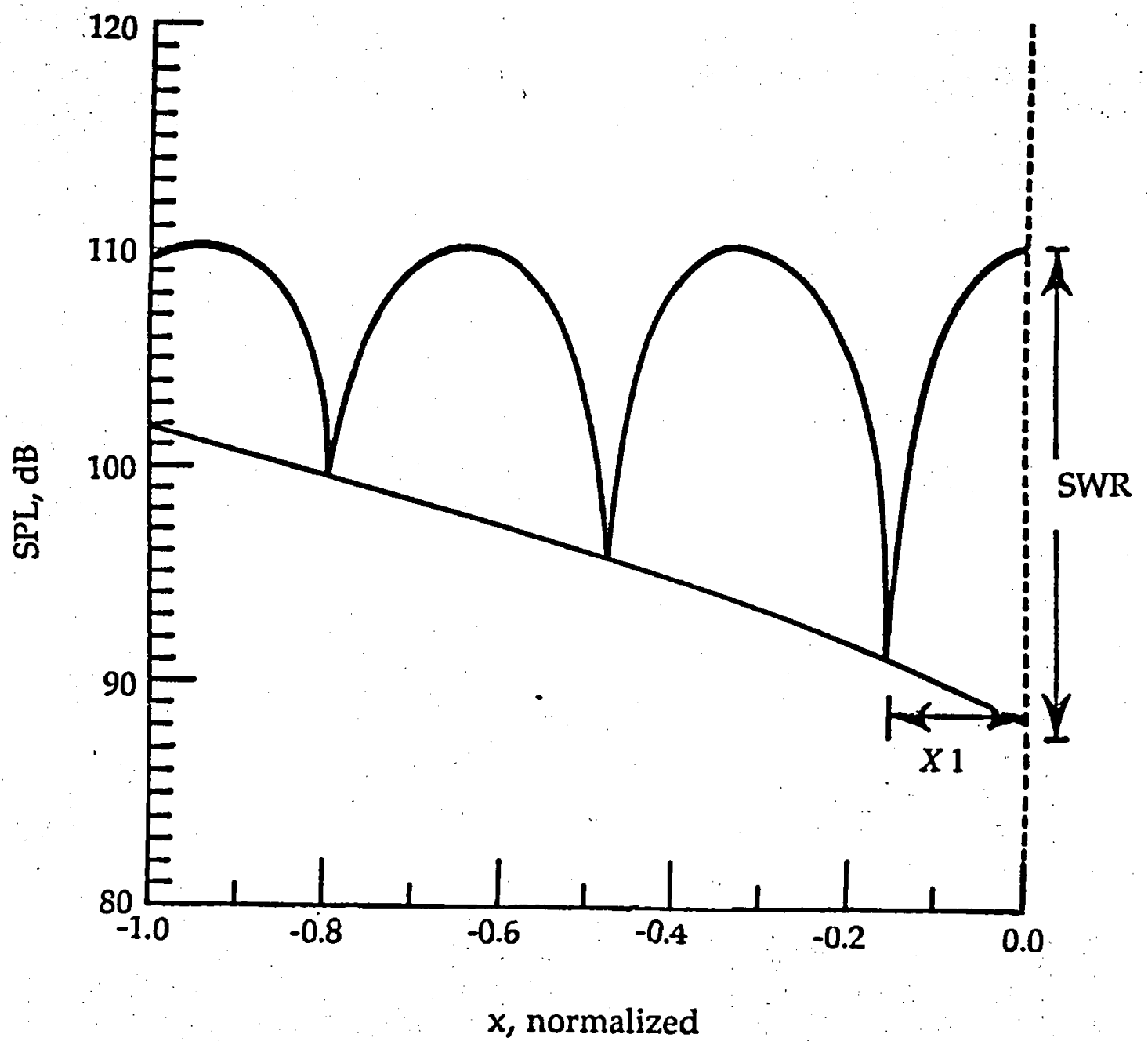

$S W R \rightarrow R F M$

$X 1 \rightarrow \theta$

$R F=R F M \bullet e^{i \theta}$

Figure 1.- Reflection factor determination from continuous plot of standing wave (face of specimen at $x=0.0$ ). 
NASA

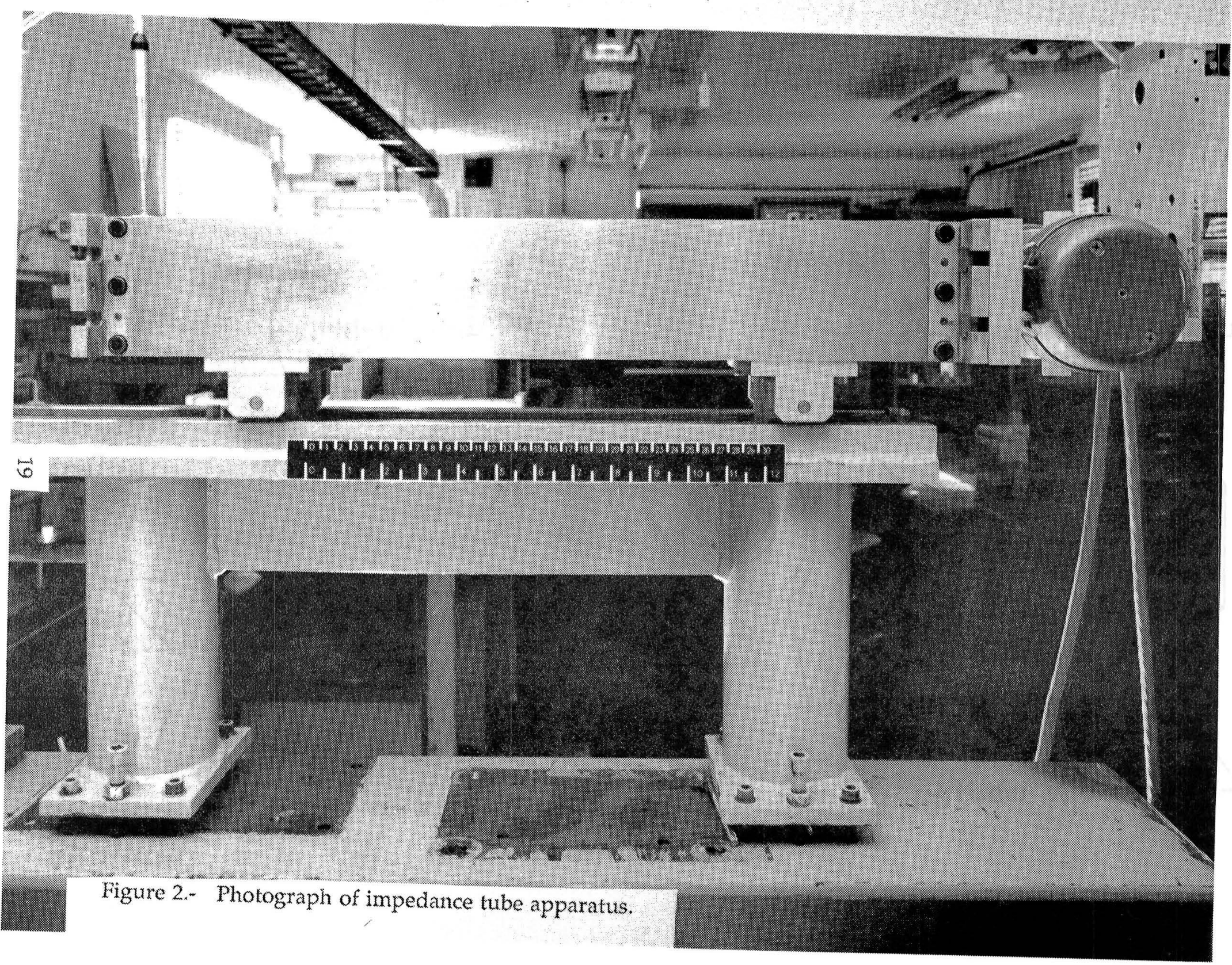




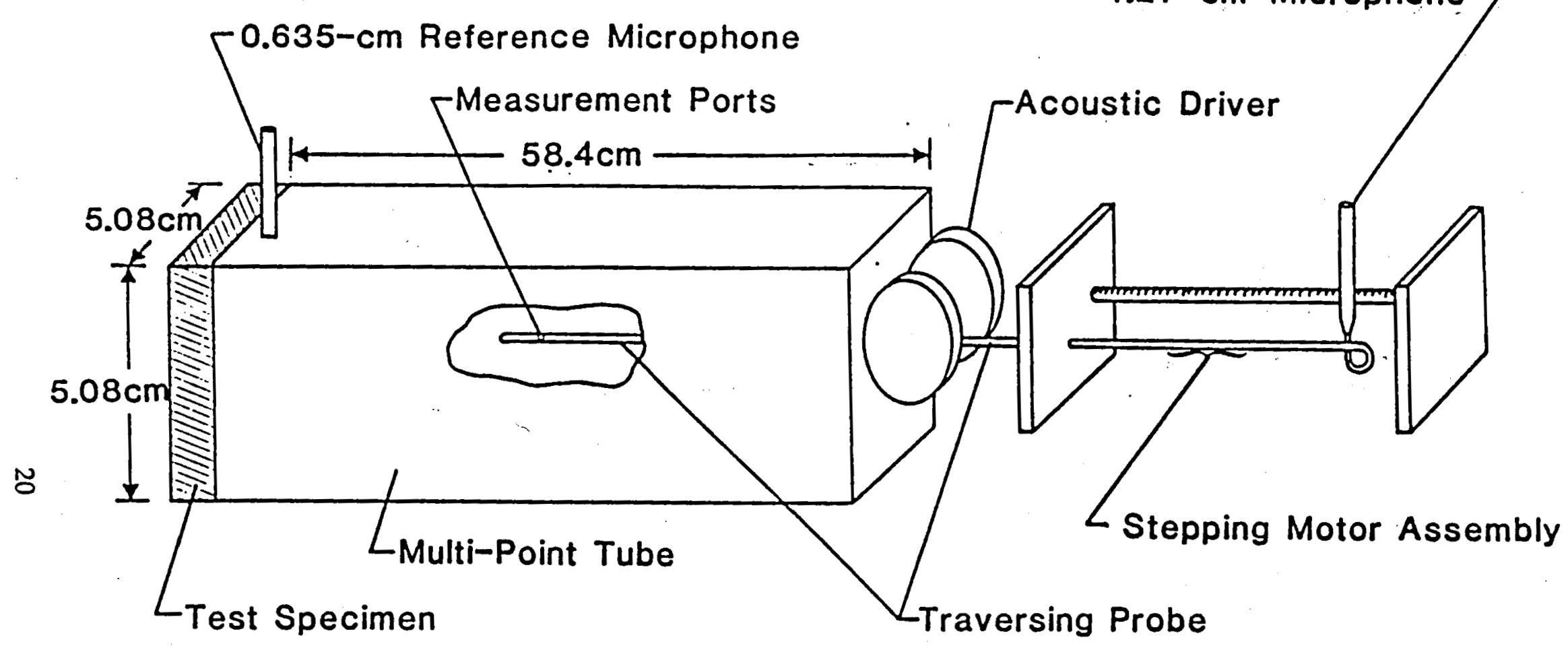

Figure 3.- Schematic of impedance tube apparatus. 


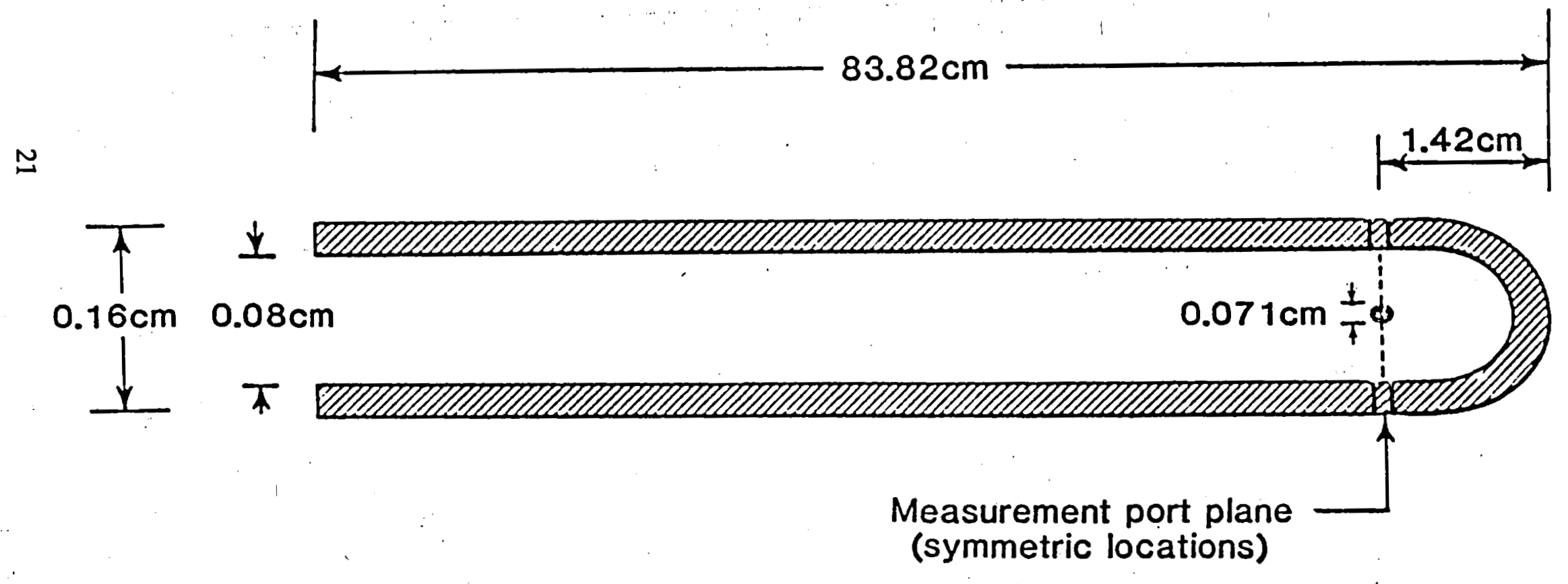

Figure 4.- Traversing probe sensing port location. 


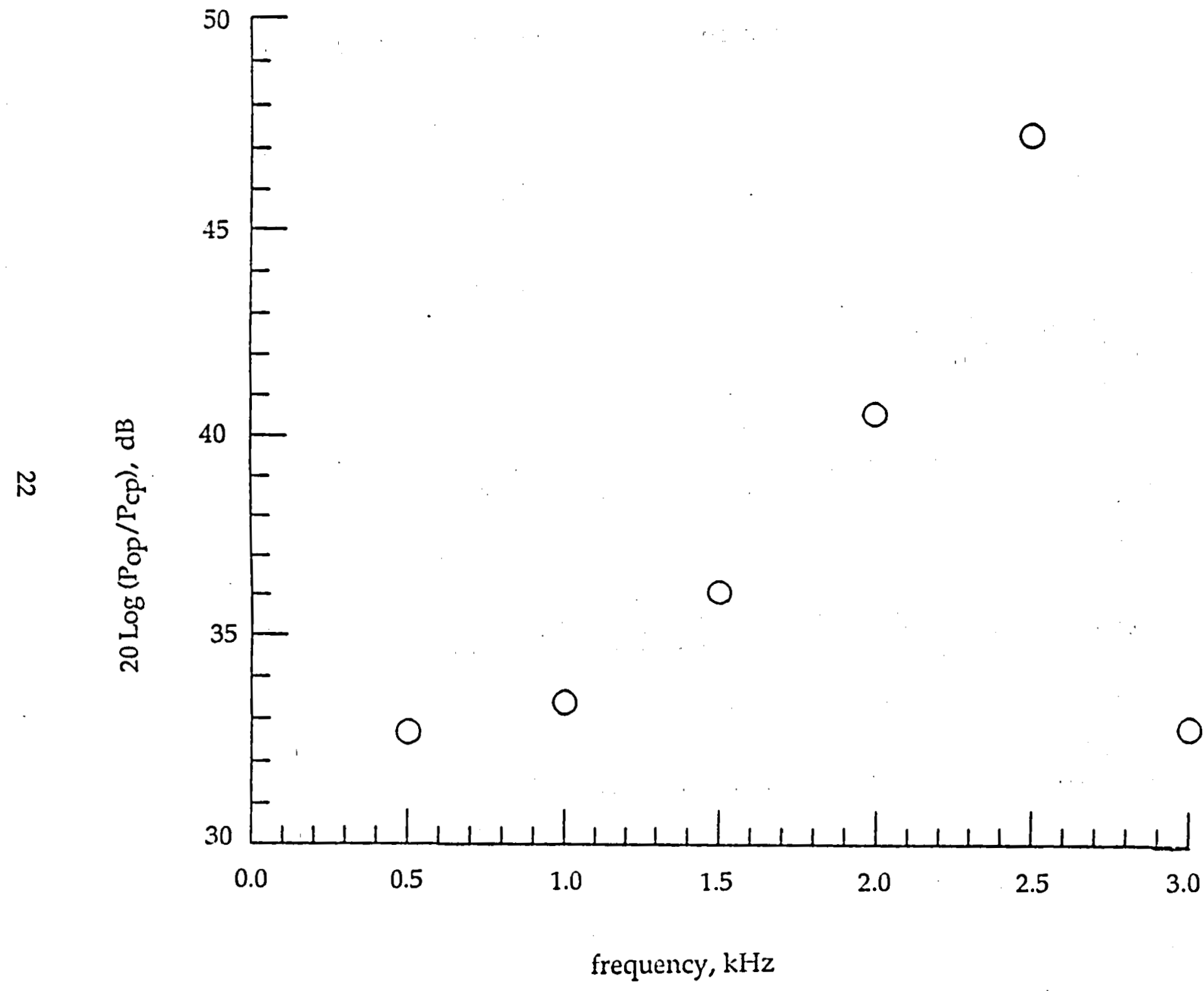

Figure 5.- Probe port insertion loss as measured by relative responses with ports open and closed-ports located at pressure null. 


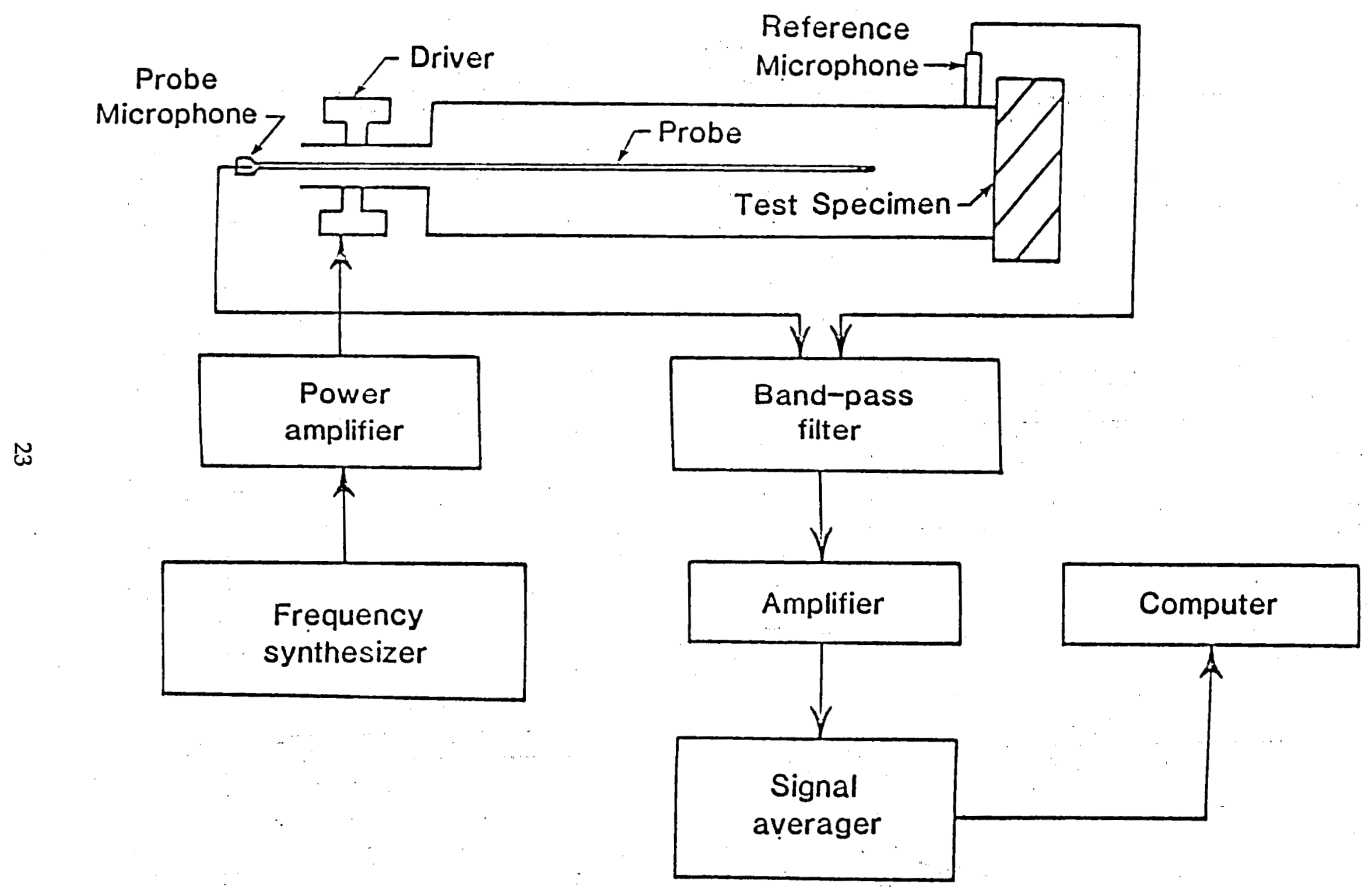

Figure 6.- Electronic instrumentation and signal conditioning schematic. 

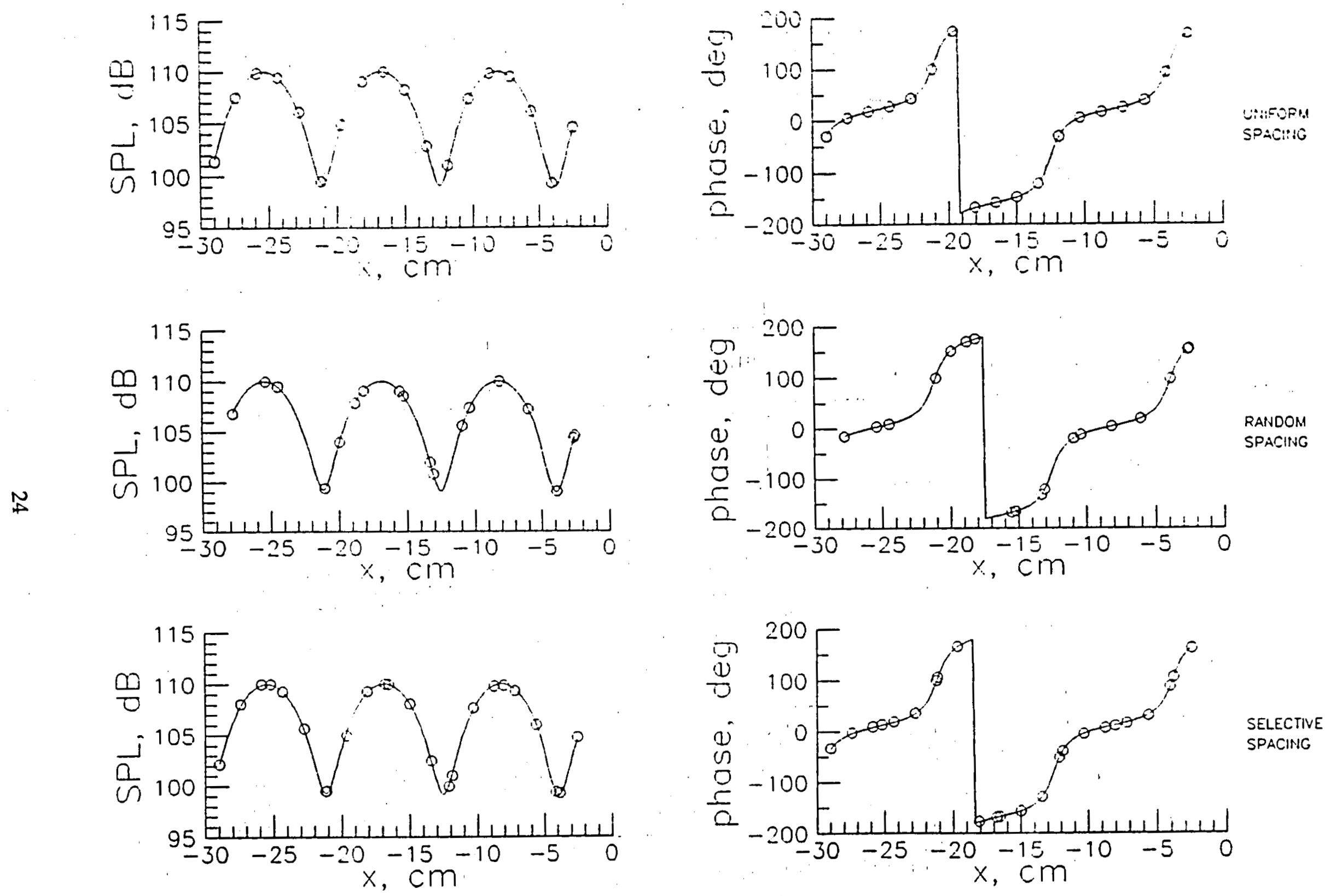

Figure 7.- Least squares fit of propagation model to discrete SPL's and phases for three measurement spacing distributions $(2 \mathrm{kHz})$.

(a) Typical SWR sample (approximately $10 \mathrm{~dB}$ ). 

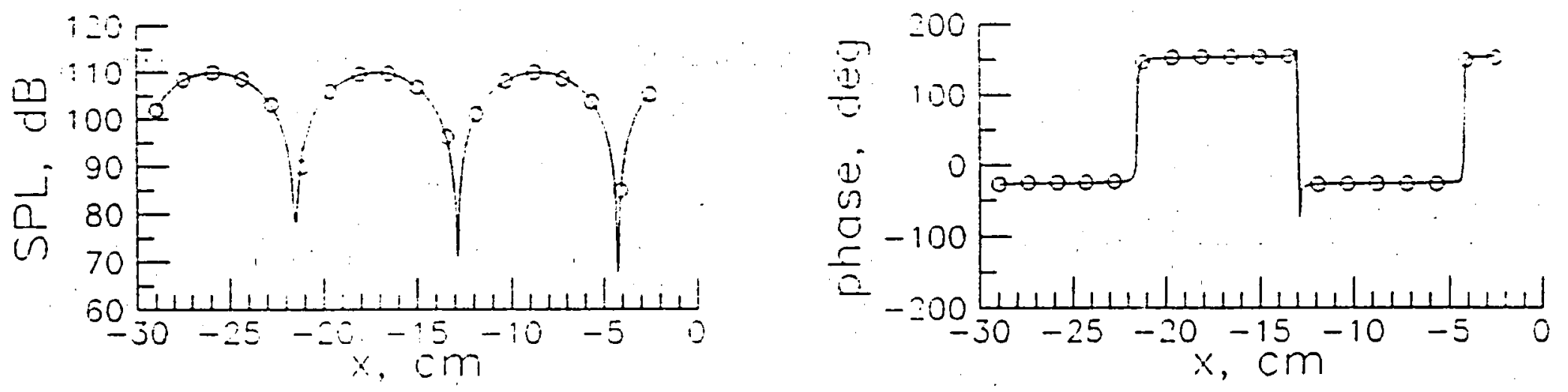

LiHESPRA SPACITHG
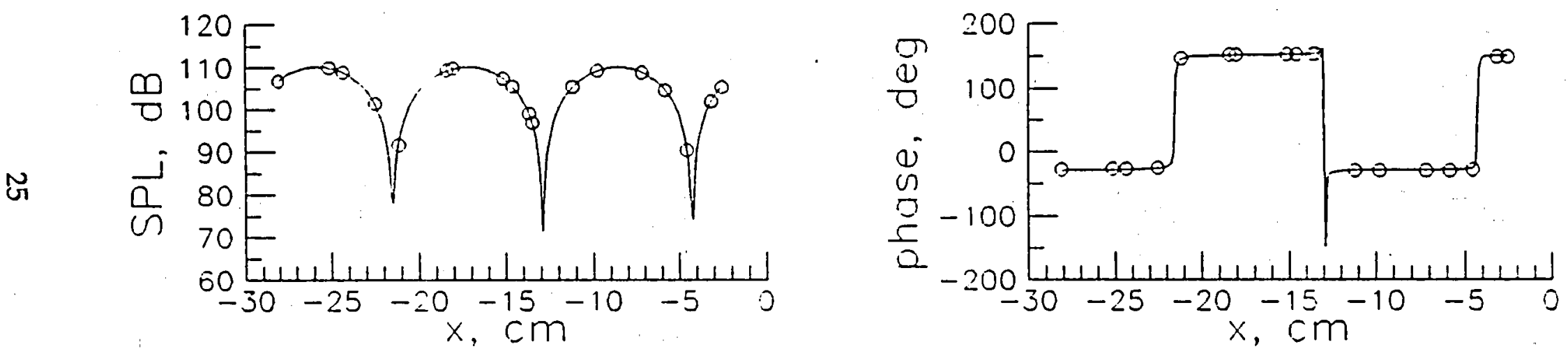

RAIIDOM SPAEING
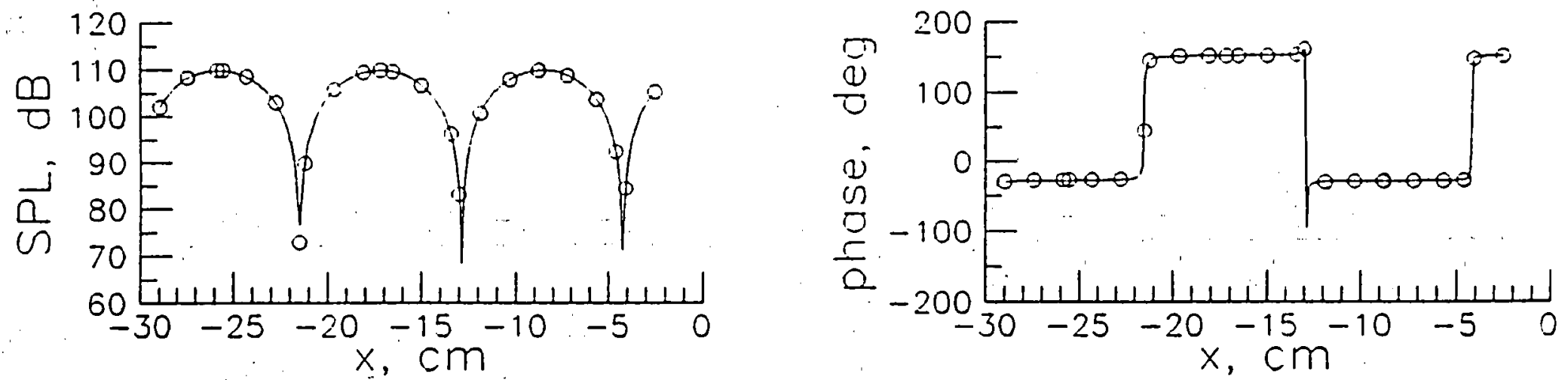

Figure 7.- (b) Large SWR sample (30 to $40 \mathrm{~dB}$ ). 

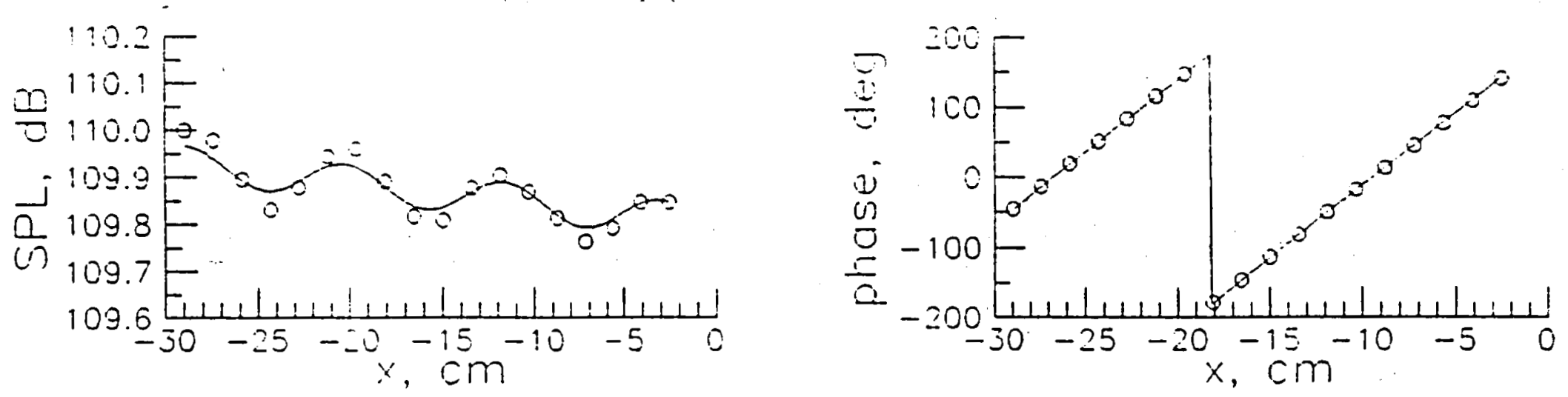

NhIF:PRh

SFAEING
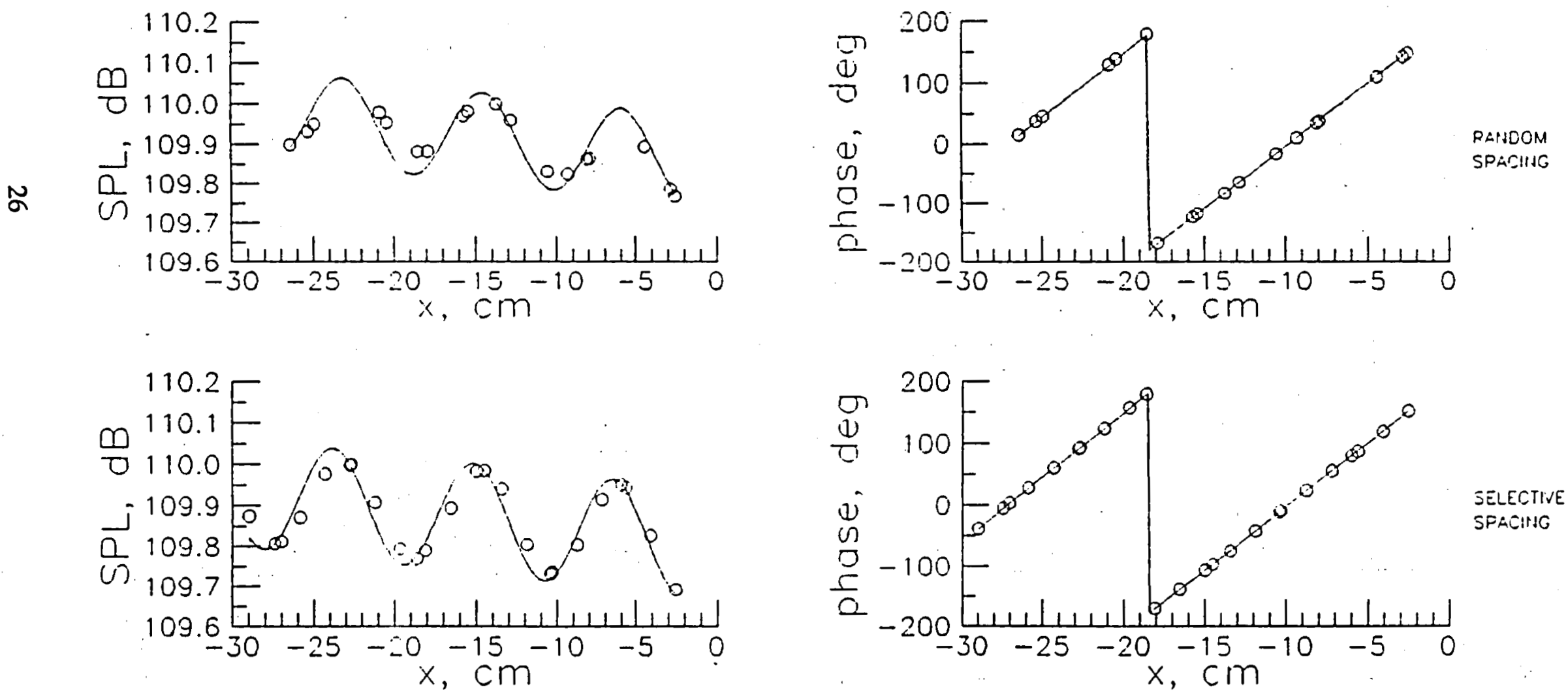

Figure 7.- (c) Small SWR sample (approximately $0.2 \mathrm{~dB}$ ). 

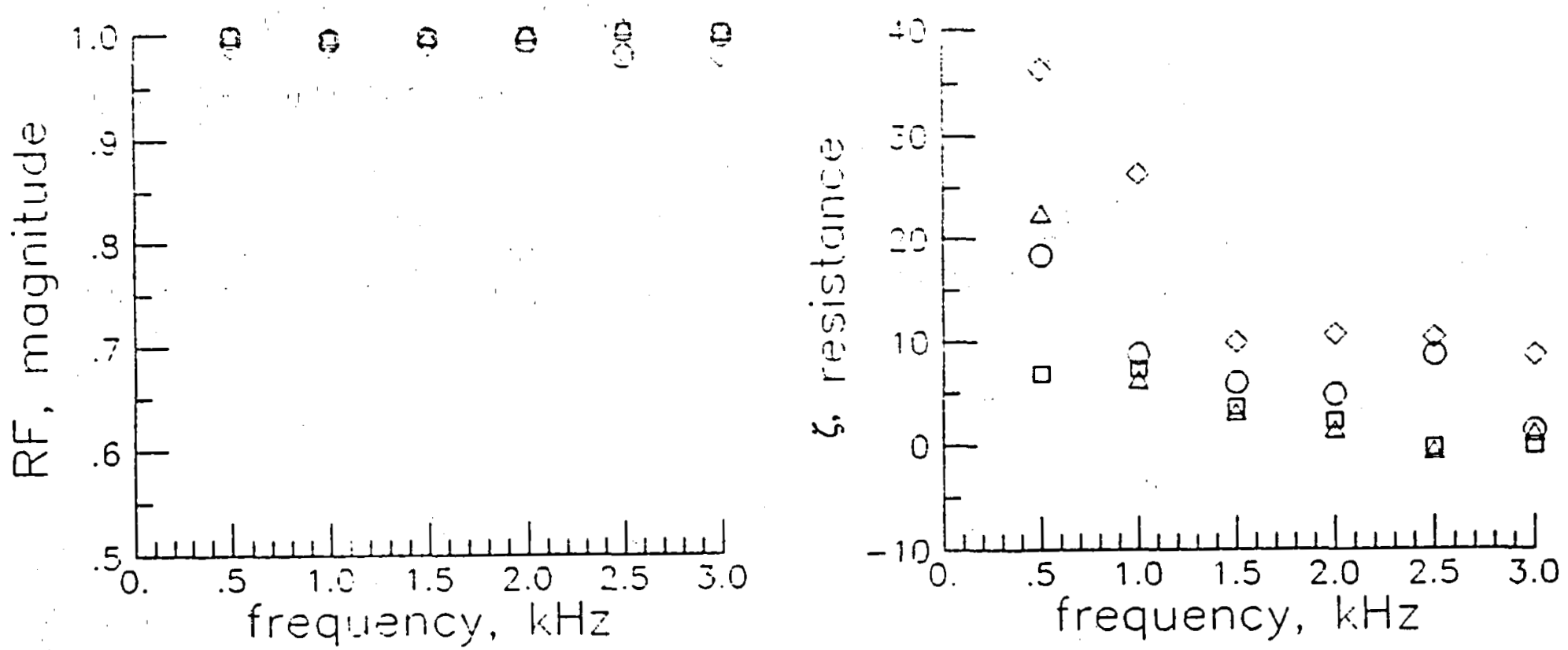

N
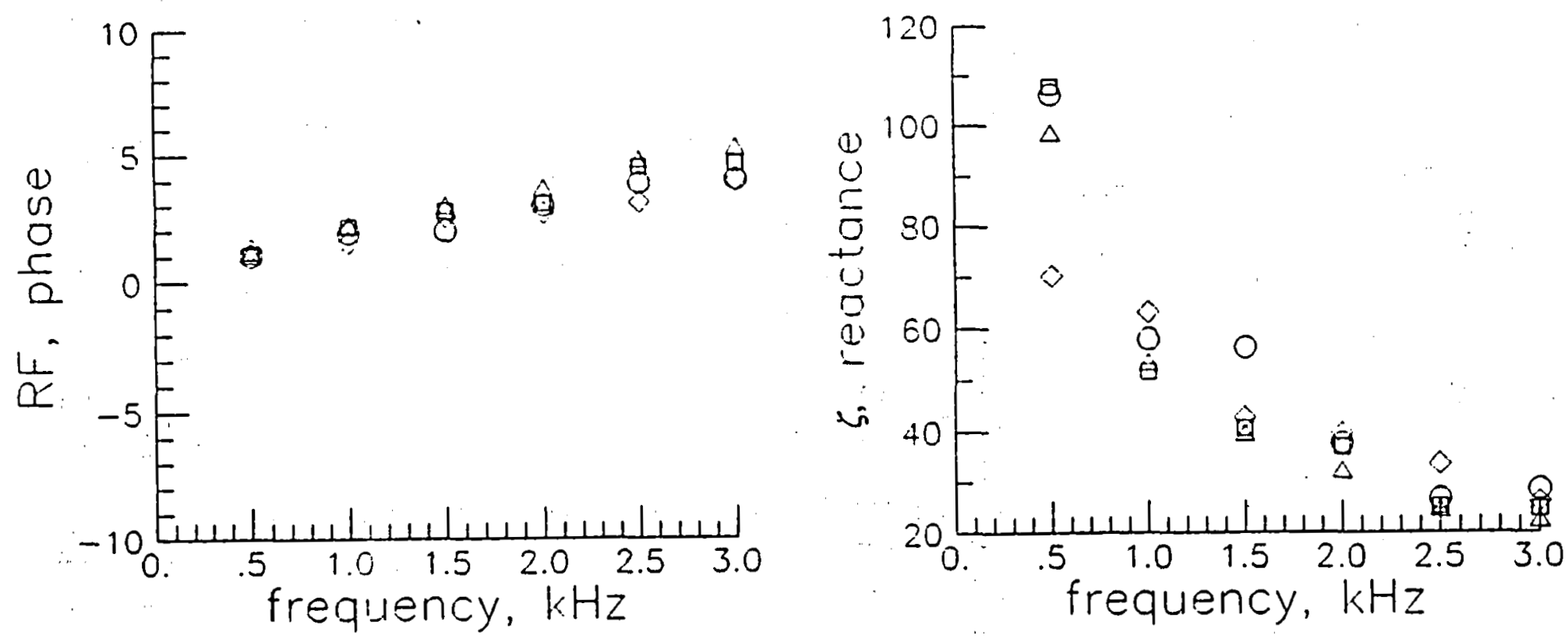

- UNIFORM

O RANDOMI

$\triangle$ SELECTIVE

$\diamond$ TMM

Figure 8.- Comparison of reflection factors and/or impedances for a variety of measurement and analysis methods. (a) Steel plate. 

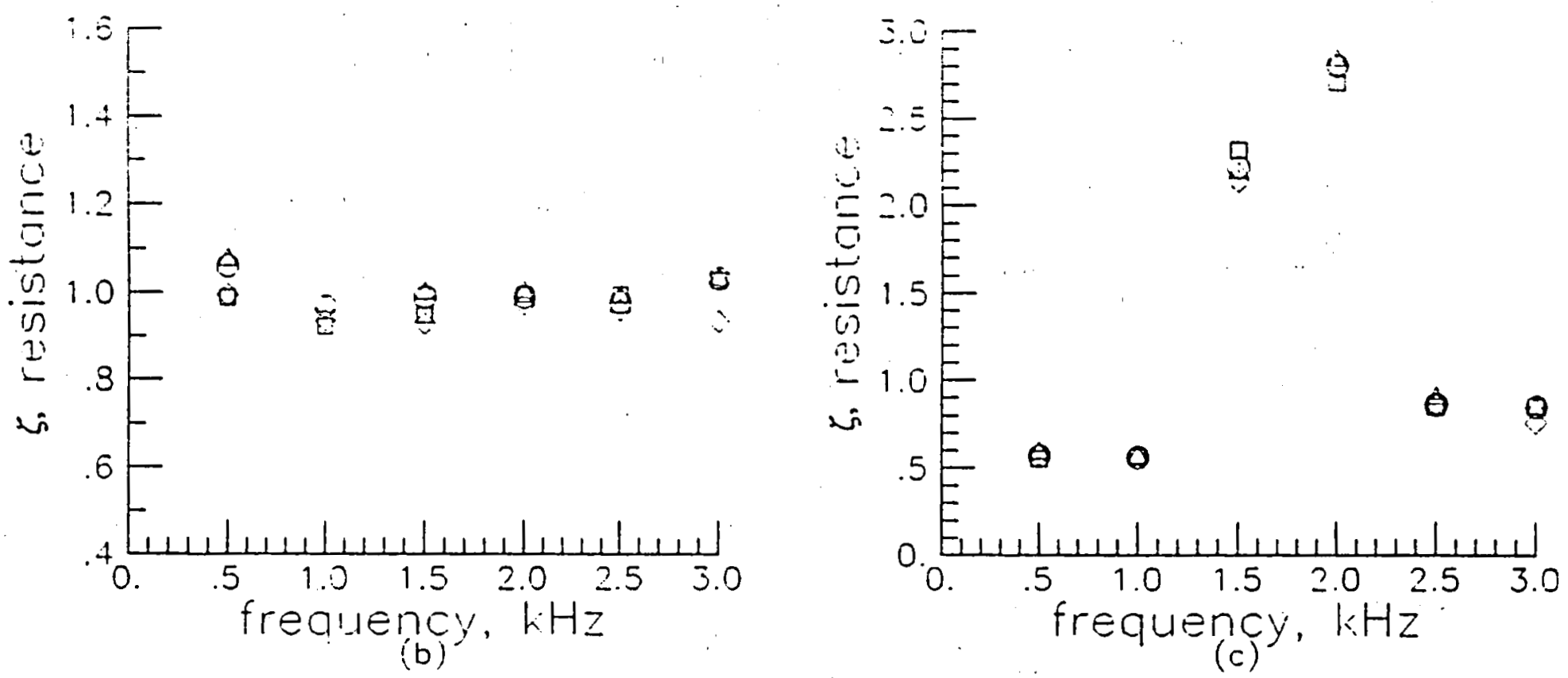

$\stackrel{\infty}{\infty}$
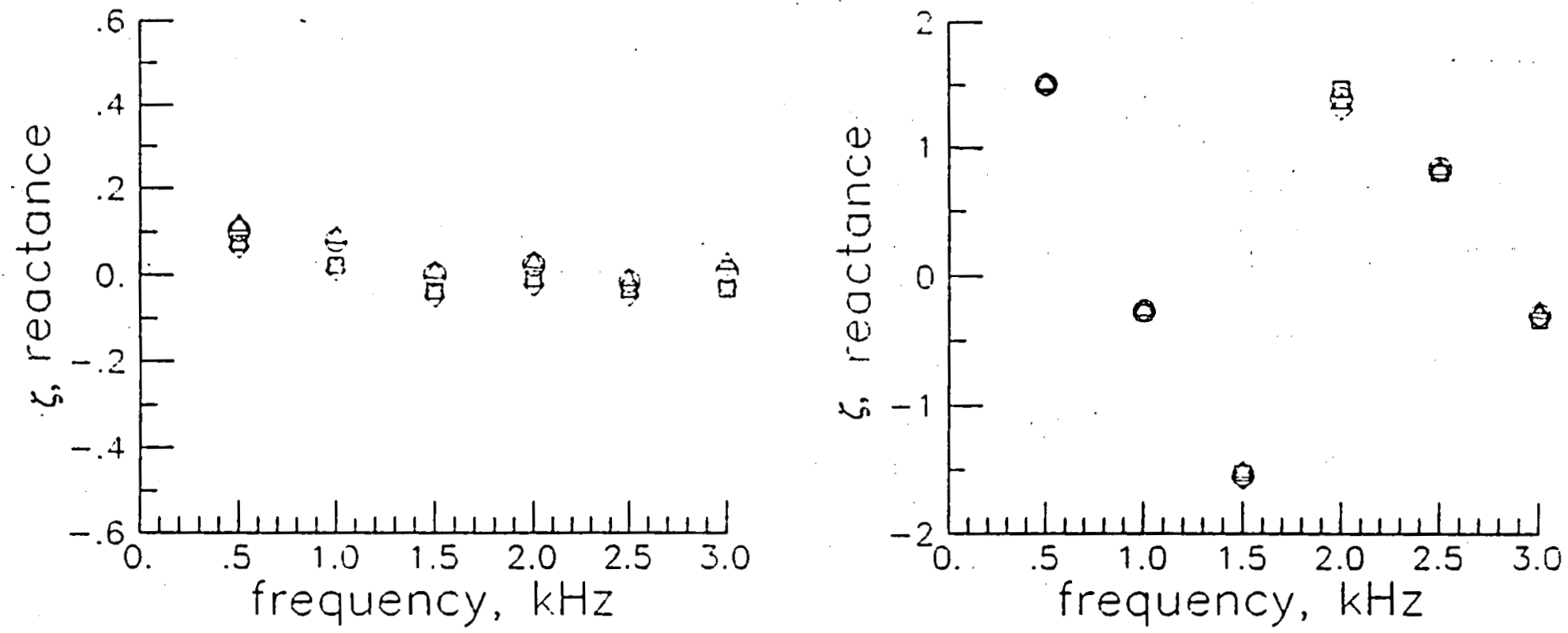

Figure 8.- (b) Foam wedge.

(c) Ceramic honeycomb. 

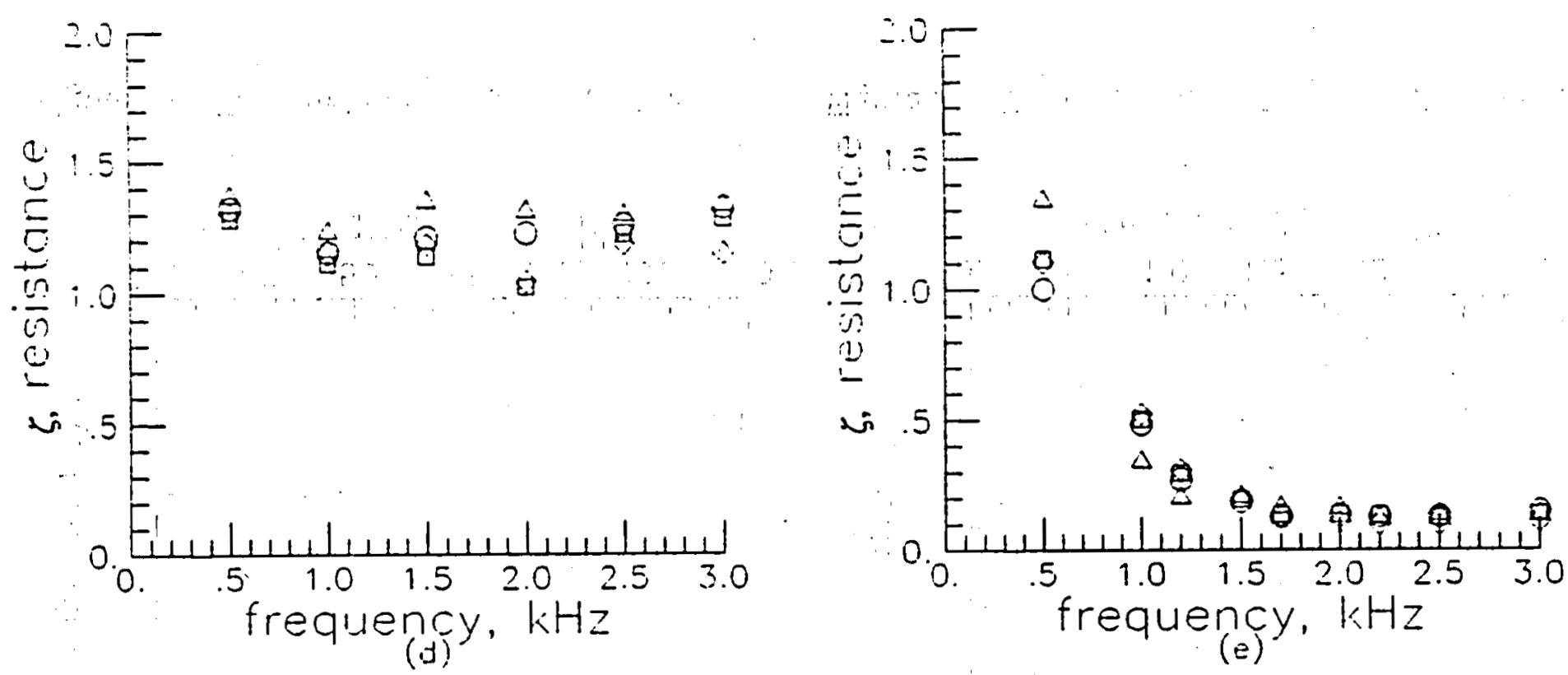

No
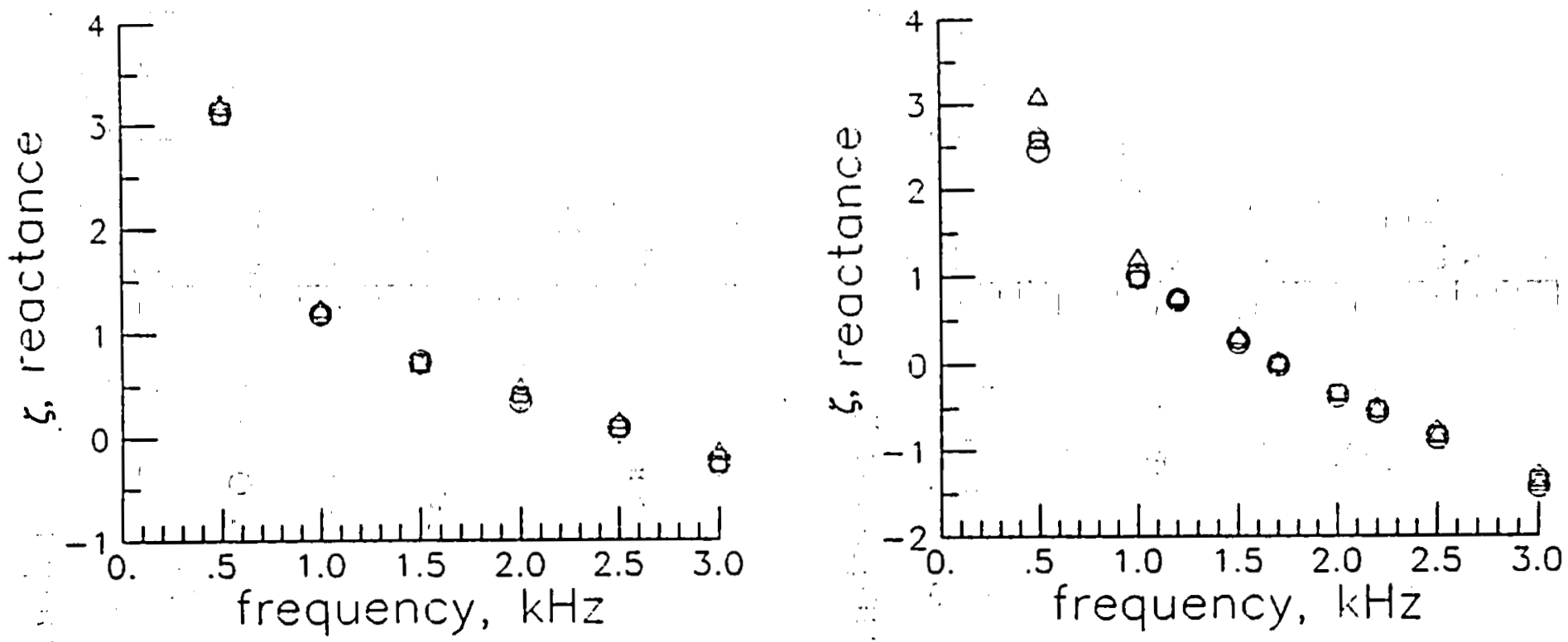

- UINIFORM

- RANCOH

$\triangle$ SELECTIVE

o TMAVI

Figure 8.- (d) Fibermetal sheet on honeycomb surface.

(e) Porous metal plate on honeycomb surface. 

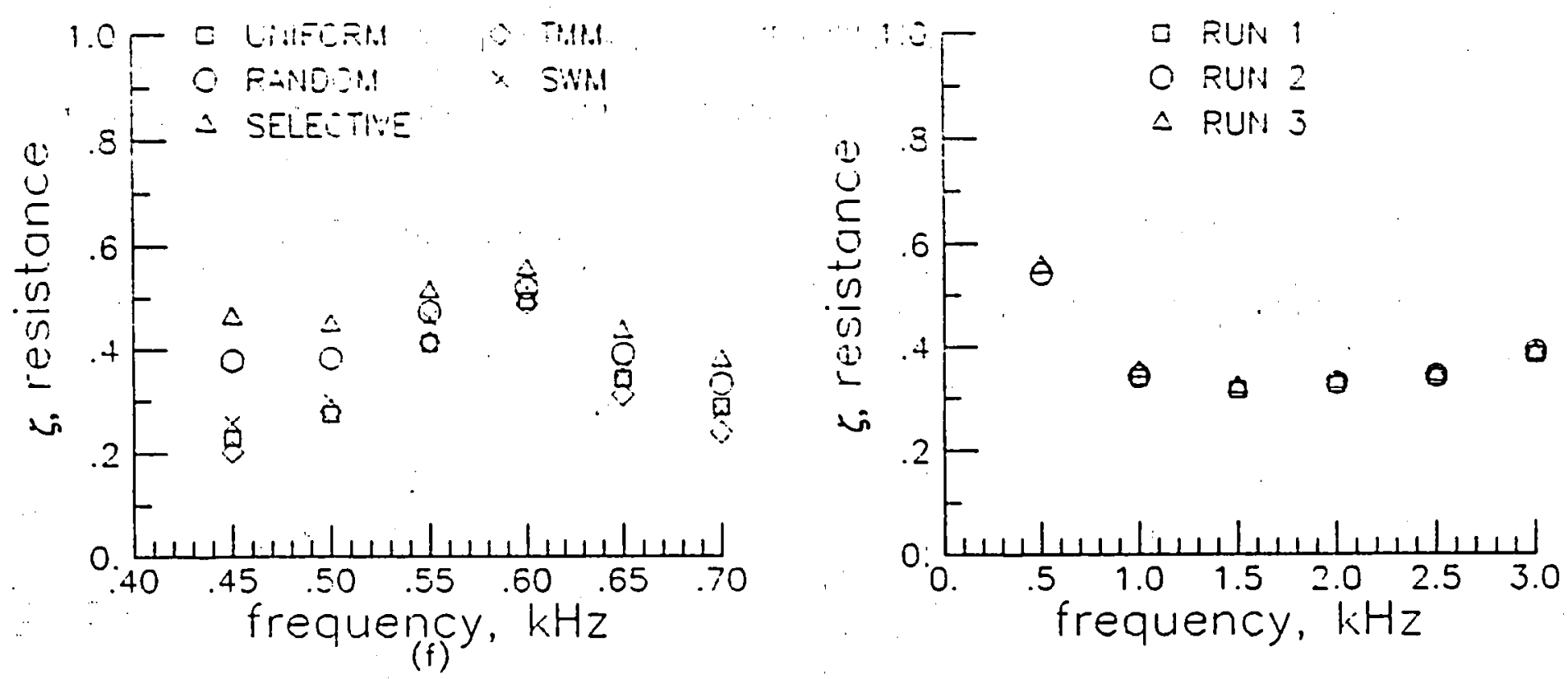

$\omega$
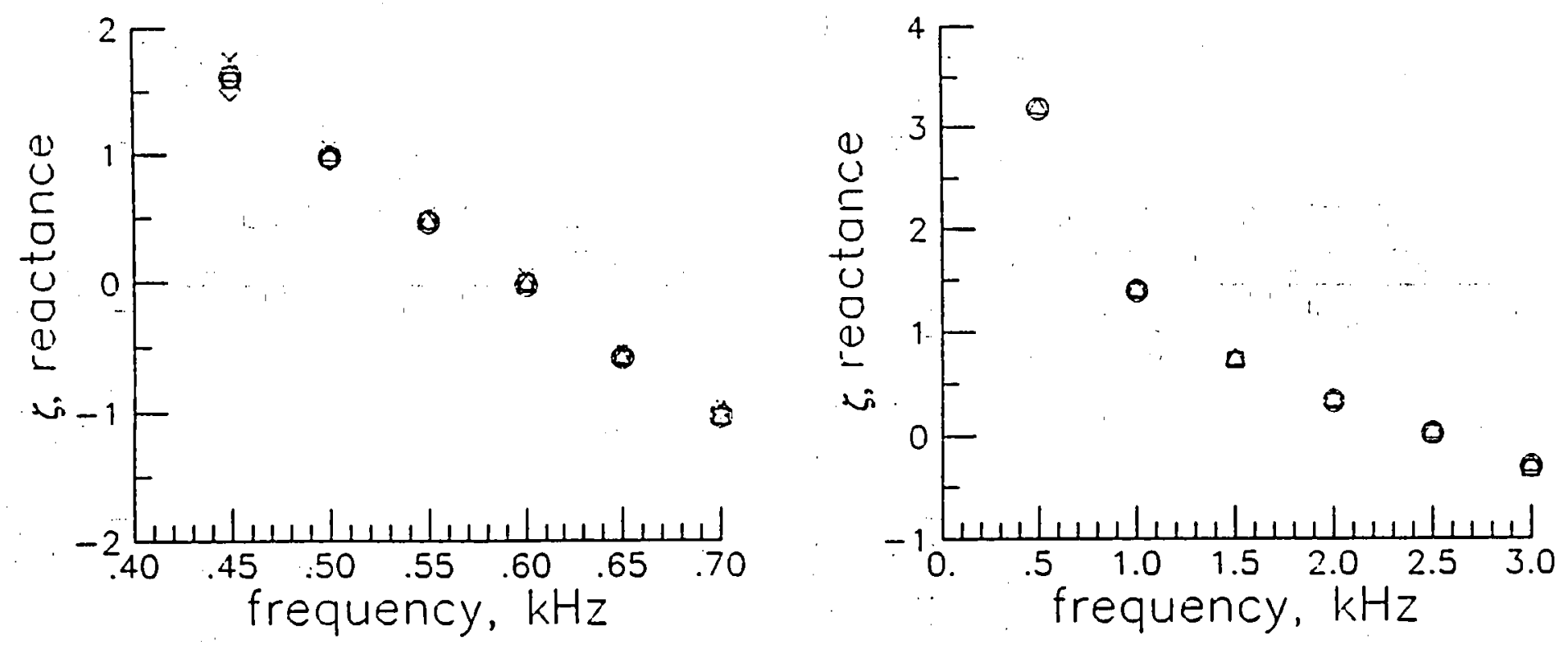

Figure 8.- (f) Aluminum plate with 4 holes.

Figure 9.- Demonstration of repeatability (uniform spacing). 

$=: 0-1 \Xi: 2$

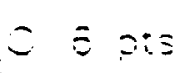
$\dot{-} \Sigma$ ois
$\$ 2$ pis
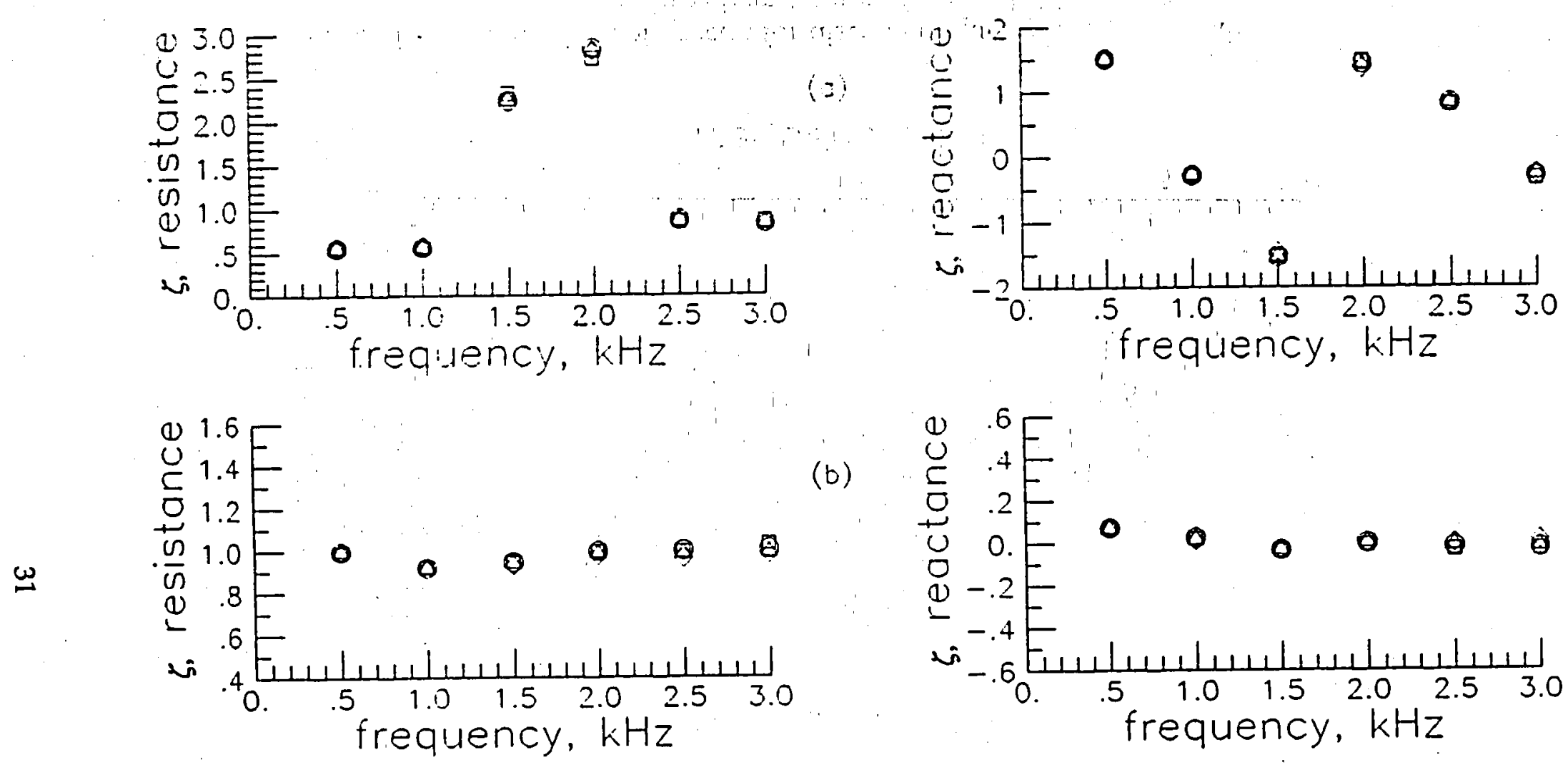

(b)
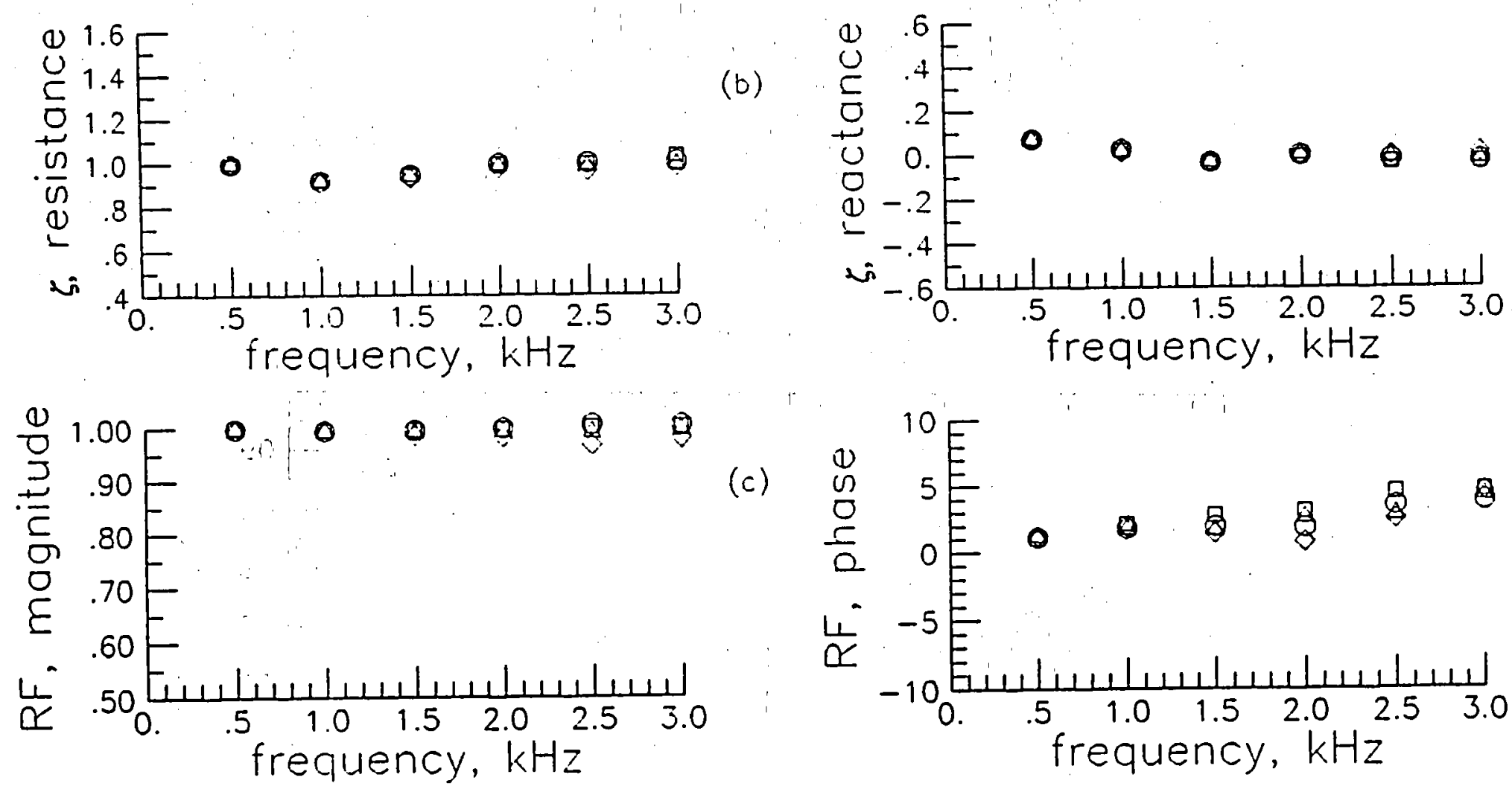

(c)

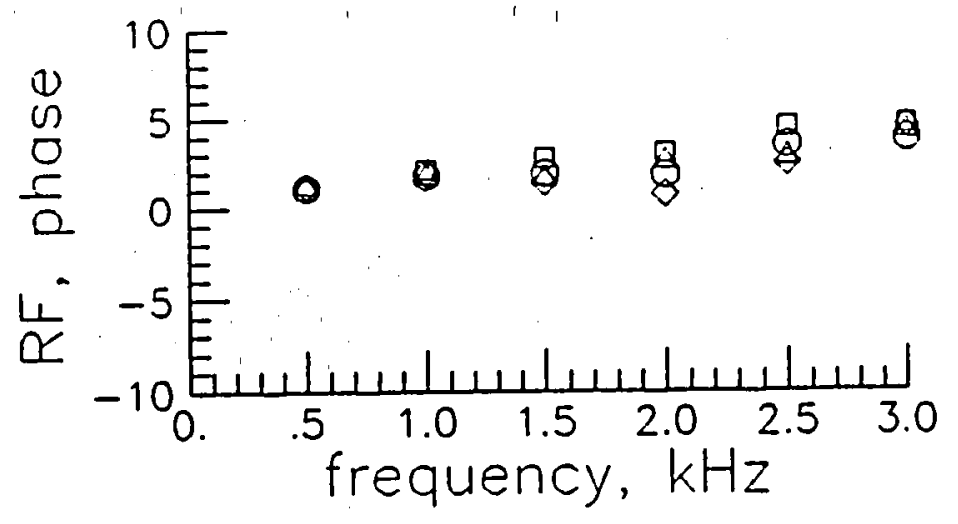

Figure 10.- Comparison of MPM results using various amounts of uniform spacing data. (a) Typical RFM (cernmic honeycomb).

(b) Small RFM (foam wedge). (c) Large RFM (steel). 


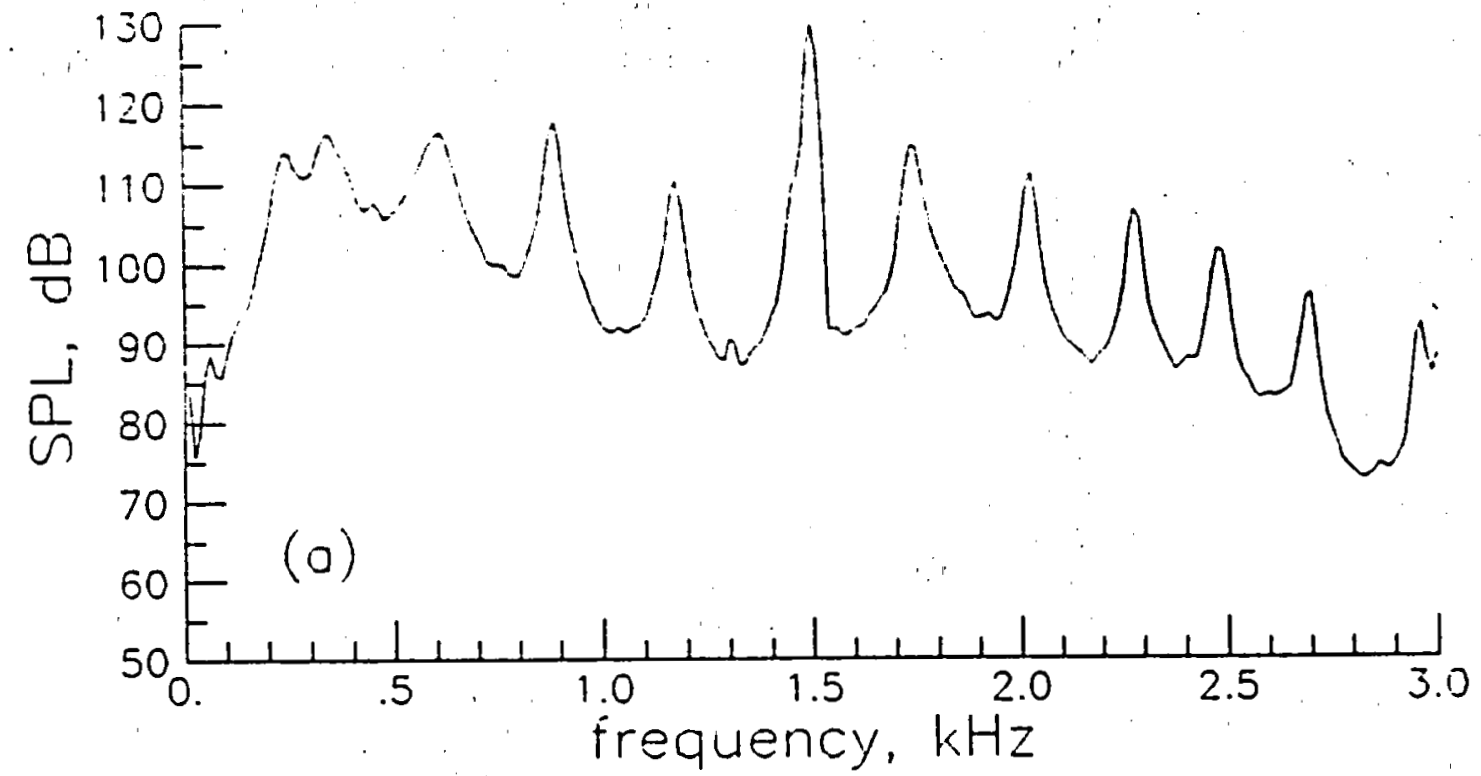

W

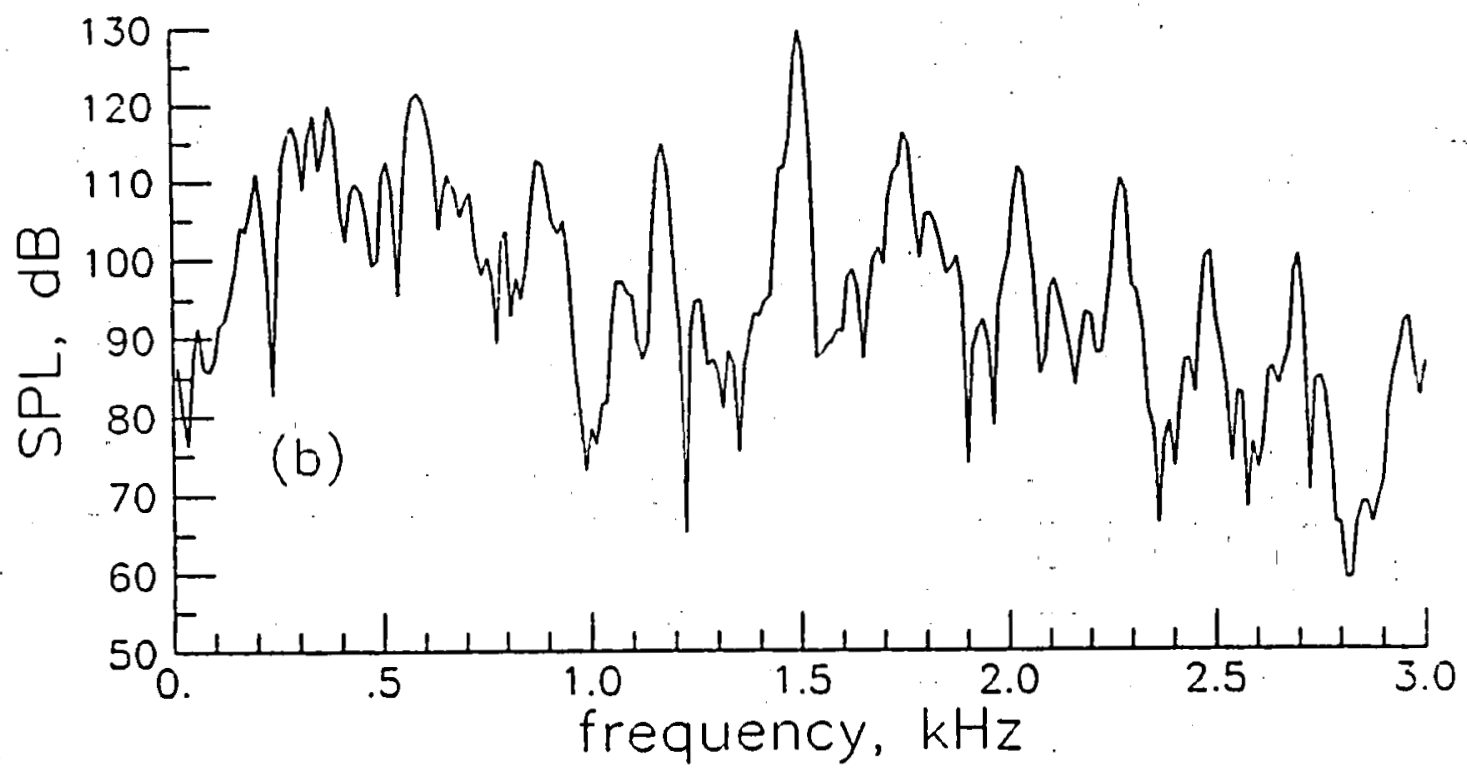

Figure 11.- Comparison of spectra for discrete frequency $(1.5 \mathrm{kHz})$ with superimposed broadband noise. (a) Small RFM test specimen. (b) Large RFM test specimen. 


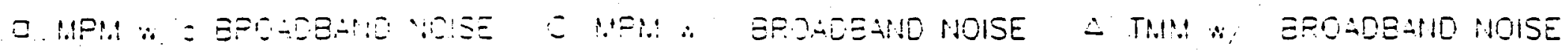
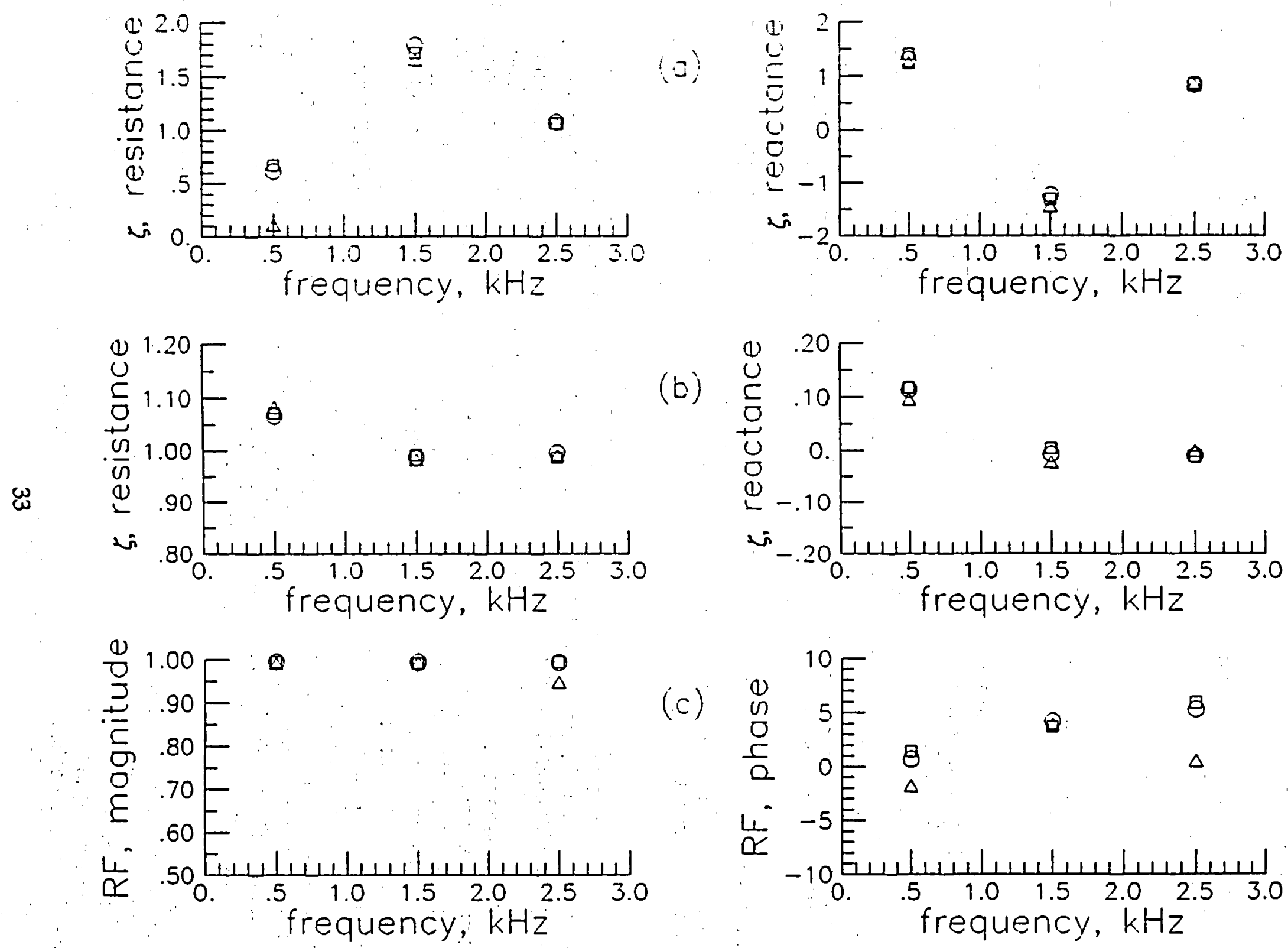

(c)

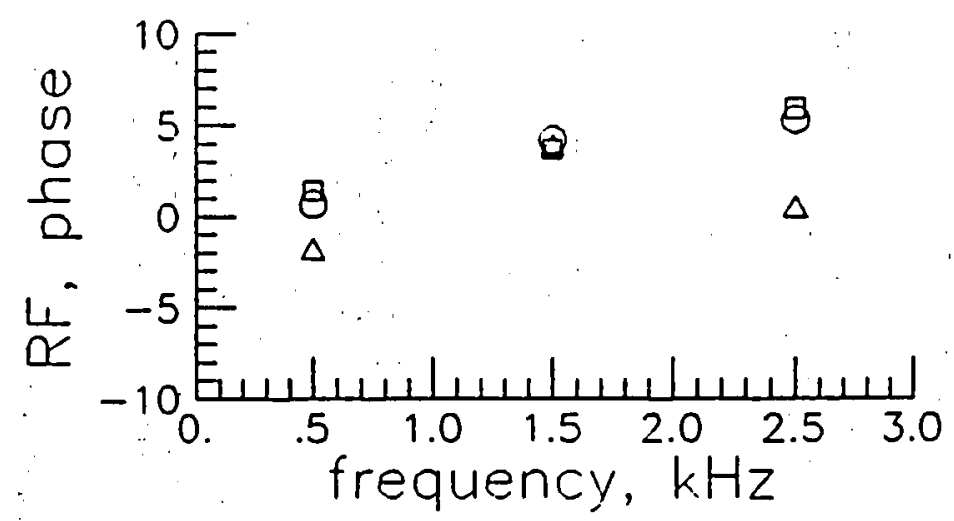

Figure 12.- Comparison of MPM and TMM results with broadband noise included.

(a) Typical RFM (ceramic honeycomb). (b) Small RFM (foam wedge).

(c) Large RFM (steel). 


\begin{tabular}{|c|c|c|c|c|}
\hline \multicolumn{5}{|c|}{ Report Documentation Page } \\
\hline $\begin{array}{l}\text { 1. Report No. } \\
\text { NASA TM-100637 }\end{array}$ & \multicolumn{2}{|c|}{ 2. Government Accession No. } & \multicolumn{2}{|c|}{ 3. Recipient's Catalog No. } \\
\hline \multirow{2}{*}{\multicolumn{3}{|c|}{$\begin{array}{l}\text { 4. Title and Subritle } \\
\text { ACOUSTIC IMPEDANCE }\end{array}$}} & \multicolumn{2}{|c|}{$\begin{array}{l}\text { 5. Report Date } \\
\text { June } 1988\end{array}$} \\
\hline & & & \multicolumn{2}{|c|}{ 6. Performing Organization Code } \\
\hline \multirow{2}{*}{\multicolumn{3}{|c|}{ Michael G. Jones and Tony L. Parrott }} & \multicolumn{2}{|c|}{ 8. Performing Organization Repon No. } \\
\hline & & & \\
\hline \multicolumn{3}{|c|}{ 9. Performing Organization Name and Address } & \multicolumn{2}{|c|}{ : $505-61-11-02$} \\
\hline \multirow{2}{*}{\multicolumn{3}{|c|}{$\begin{array}{l}\text { Langley Research Center } \\
\text { Hampton, VA } 23665-5225\end{array}$}} & \multicolumn{2}{|c|}{$\begin{array}{c}11 . \text { Contract or Grant No. } \\
\vdots\end{array}$} \\
\hline & & & \multirow{2}{*}{\multicolumn{2}{|c|}{$\begin{array}{l}\text { 13. Type of Report and Period Covered } \\
\text { Technical Memorandum }\end{array}$}} \\
\hline \multirow{2}{*}{\multicolumn{3}{|c|}{$\begin{array}{l}\text { 12. Sponsoring Agency Name and Address } \\
\text { National Aeronautics and Space Administration } \\
\text { Washington, DC 20546-0001 }\end{array}$}} & & \\
\hline & & & 14. Sponsoring $A$ & Code \\
\hline \multicolumn{5}{|c|}{$\begin{array}{l}\text { Michael G. Jones, Planning Research Corporation, Hampton, Virginia. } \\
\text { Tony L. Parrott, Langley Research Center, Hampton, Virginia. }\end{array}$} \\
\hline \multicolumn{5}{|c|}{$\begin{array}{l}\text { 16. Abstract An investigation was conducted to explore potential improvements } \\
\text { provided by a Multi-Point Method (MPM) over the Standing Wave Method (SWM) and Two- } \\
\text { Microphone Method (TMM) for determining acoustic impedance. A wave propagation } \\
\text { model was developed to model the standing wave pattern in an impedance tube. The } \\
\text { acoustic impedance of a test specimen was calculated from a 'best' fit of this standing wave } \\
\text { pattern to pressure measurements obtained along the impedance tube centerline. Three } \\
\text { measurement spacing distributions were examined; uniform, random, and selective. } \\
\text { Calculated standing wave patterns match the point pressure measurement distributions } \\
\text { with good agreement for a reflection factor magnitude range of } 0.004 \text { to } 0.999 \text {. } \\
\text { Comparisons of results using } 2,3,6 \text {, and } 18 \text { measurement points showed that the most } \\
\text { consistent results are obtained when using at least } 6 \text { evenly spaced pressure } \\
\text { measurements per half-wavelength. Also, data were acquired with broadband noise added } \\
\text { to the discrete frequency noise and impedances were calculated using the MPM and TMM } \\
\text { algorithms. The results indicate that the MPM will be superior to the TMM in the presence of } \\
\text { significant broadband noise levels associated with mean flow. }\end{array}$} \\
\hline \multicolumn{2}{|c|}{$\begin{array}{l}\text { 17. Key words (Suggested by Author(s) } \\
\text { Acoustic impedance measurement } \\
\text { Reflection factor } \\
\text { Normal incidence } \\
\text { Multi-point method Mean flow } \\
\text { Two-microphone method }\end{array}$} & $\begin{array}{l}\text { 18. Distribution } \\
\text { Unclass }\end{array}$ & dent - Unlimite & \\
\hline $\begin{array}{l}\text { 19. Security Classit. lof this reportl } \\
\text { Unclass if ied }\end{array}$ & \begin{tabular}{r|r}
$\begin{array}{r}\text { 20. Security Classif. Iof } \\
\text { Unclassified }\end{array}$
\end{tabular} & his pagel & $\begin{array}{l}\text { 21. No. of pages } \\
35\end{array}$ & $\begin{array}{r}\text { 22. Price } \\
\text { A03 }\end{array}$ \\
\hline
\end{tabular}

NASA FORM 1026 OCT 86 